\title{
Electron Bifurcating FixABCX Protein Complex from Azotobacter vinelandii: Generation of Low-Potential Reducing Equivalents for Nitrogenase Catalysis
}

Authors: Rhesa N. Ledbetter, Amaya M. Garcia Costas, Carolyn E. Lubner, David W. Mulder, Monika Tokmina-Lukaszewska, Jacob H. Artz, Angela Patterson, Timothy S. Magnuson, Zackary J. Jay, H. Diessel Duan, Jacquelyn Miller, Mary H. Plunkett, John P. Hoben, Brett M. Barney, Ross P. Carlson, Anne-Frances Miller, Brian Bothner, Paul W. King, John W. Peters, \& Lance C. Seefeldt

This document is the unedited author's version of a Submitted Work that was subsequently accepted for publication in Biochemistry, copyright (C) American Chemical Society after peer review. To access the final edited and published work, see https://doi.org/10.1021/ acs.biochem.7b00389.

Ledbetter RN, Amaya M. Garcia Costas, Carolyn E. Lubner, David W. Mulder, Monika TokminaLukaszewska, Jacob H. Artz, Angela Patterson, Timothy S. Magnuson, Zackary J. Jay, H. Dissel Duan, Jacquelyn Miller, Mary H. Plunkett, John P. Hoben, Brett M. Barney, Ross P. Carlson, Anne-Frances Miller, Brian Bothner, Paul W. King, John W. Peters, Lance C. Seefeldt, "The Electron Bifurcating FixABCX Protein Complex from Azotobacter Vinelandii: Generation of LowPotential Reducing Equivalents for Nitrogenase Catalysis." Biochemistry 56, no. 32 (August 3, 2017): 4177-4190. 


\section{The Electron Bifurcating FixABCX Protein Complex from Azotobacter vinelandii: Generation of Low-Potential Reducing Equivalents for Nitrogenase Catalysis}

Rhesa N. Ledbetter, Amaya M. Garcia Costas, Carolyn E. Lubner, David W. Mulder, Monika Tokmina-Lukaszewska, Jacob H. Artz, Angela Patterson, Timothy S. Magnuson, Zackary J. Jay, H. Diessel Duan, Jacquelyn Miller, Mary H. Plunkett, John P. Hoben, Brett M. Barney, Ross P. Carlson, Anne-Frances Miller, Brian Bothner, Paul W. King, John W. Peters and Lance C. Seefeldt

\footnotetext{
The biological reduction of dinitrogen $\left(\mathrm{N}_{2}\right)$ to ammonia $\left(\mathrm{NH}_{3}\right)$ by nitrogenase is an energetically demanding reaction that requires low-potential electrons and ATP; however, pathways used to deliver the electrons from central metabolism to the reductants of nitrogenase, ferredoxin or flavodoxin, remain unknown for many diazotrophic microbes. The FixABCX protein complex has been proposed to reduce flavodoxin or ferredoxin using NADH as the electron donor in a process known as electron bifurcation. Herein, the FixABCX complex from Azotobacter vinelandii was purified and demonstrated to catalyze an electron bifurcation reaction: oxidation of NADH $\left(\mathrm{E}_{\mathrm{m}}=-320 \mathrm{mV}\right)$ coupled to reduction of flavodoxin semiquinone $\left(\mathrm{E}_{\mathrm{m}}=-460 \mathrm{mV}\right)$ and reduction of coenzyme Q $\left(\mathrm{E}_{\mathrm{m}}=10 \mathrm{mV}\right)$. Knocking out fix genes rendered $\Delta \mathrm{rnf}$ A. vinelandii cells unable to fixdinitrogen,confirming that the FixABCX system provides another route for delivery of electrons to nitrogenase. Characterization of the purified FixABCX complex revealed the presence of flavin and iron-sulfur cofactors confirmed by native mass spectrometry, electron paramagnetic resonance spectroscopy, and transient absorption spectroscopy. Transient absorption spectroscopy further established the presence of a short-lived flavin semiquinone radical, suggesting that a thermodynamically unstable flavin semiquinone may participate as an intermediate in the transfer of an electron to flavodoxin. A structural model of FixABCX, generated using chemical cross-linking in conjunction with homology modeling, revealed plausible electron transfer pathways to both high- and low-potential acceptors. Overall, this study informs a mechanism for electron bifurcation, offering insight into a unique method for delivery of low-potential electrons required for energy-intensive biochemical conversions.
}

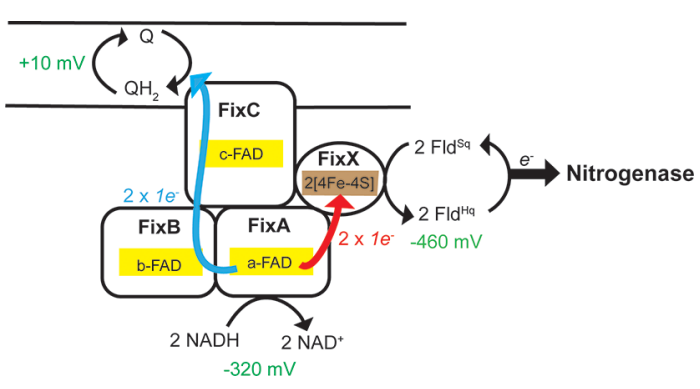

Biological dinitrogen $\left(\mathrm{N}_{2}\right)$ fixation is performed by diazotrophic microbes, which harbor the enzyme nitro-genase. This enzyme converts N2 into bioavailable ammonia (NH3)(eq 1) and accounts for at least half of the production of fixed nitrogen on Earth. 1-3
As summarized by eq 1 , the biological reduction of $\mathrm{N}_{2}$ is an energy-demanding reaction, requiring both ATP and low-reduction potential electrons. These electrons are provided by small redox proteins, ferredoxin $(\mathrm{Fd})$ and flavodoxin (Fld), which serve as direct donors of electrons to the iron $(\mathrm{Fe})$ protein

$$
\begin{aligned}
& \mathrm{N}_{2}+8 \mathrm{H}^{+}+16 \mathrm{MgATP} \quad 8 \mathrm{e}^{-} \\
& \rightarrow 2 \mathrm{NH}_{3}+\mathrm{H}_{2}+16 \mathrm{MgADP}+16 \mathrm{P}_{\mathrm{i}}
\end{aligned}
$$


of nitrogenase. ${ }^{4-10}$ The redox active iron-sulfur clusters of $\mathrm{Fd}$ typically access one redox couple $\left(\mathrm{Fd}^{\mathrm{Ox} / \mathrm{Red}}\right)$ with midpoint reduction potentials $\left(E_{\mathrm{m}}\right)$ ranging from 0 to $-645 \mathrm{mV}$. ${ }^{411}$ Two redox couples of the flavin in Fld are accessible, including the oxidized quinone/semiquinone (Fld ${ }^{\mathrm{Ox} / \mathrm{Sq}}$ ) and semiquinone/ hydroquinone $\left(\mathrm{Fld}^{\mathrm{Sq} / \mathrm{Hq}}\right)$ couples. ${ }^{5,9,12}$ In general, the $E_{\mathrm{m}}$ of the Fld ${ }^{\mathrm{Ox} / \mathrm{Sq}}$ couple ranges from -50 to $-250 \mathrm{mV}$ and that of the $\mathrm{Fld}^{\mathrm{Sq} / \mathrm{Hq}}$ couple from -370 to $-500 \mathrm{mV} .^{4,7}$ Only the $\mathrm{Fld}^{\mathrm{Sq} / \mathrm{Hq}}$ couple of Fld has enough driving force to donate electrons to nitrogenase. While much is known about other aspects of biological nitrogen fixation, pathways for delivery of the lowpotential reducing equivalents for $\mathrm{Fd}$ and Fld reduction are not well understood for many diazotrophs. ${ }^{4}$ It has been shown that the nitrogen-fixing organism Klebsiella pneumoniae uses the anaerobic oxidation of pyruvate to reduce Fld, ${ }^{13,14}$ and it was proposed that other microbes likely use energy associated with the proton motive force to drive reduction of a low-potential electron donor. ${ }^{15,16}$

Recently, a new mechanism for generating a reductant for nitrogen fixation was put forward. Flavin-based electron bifurcation (FBEB), considered a third fundamental form of energy conservation, couples exergonic and endergonic electron transfer reactions to limit free energy loss in biological systems. ${ }^{17-19}$ FBEB exploits a favorable electron transfer event to drive a thermodynamically unfavorable reaction without the use of ATP or an electrochemical gradient. ${ }^{17-19}$ Several bifurcating complexes, all of which contain a flavin as the proposed site of bifurcation, have been identified in anaerobic bacteria and archaea. ${ }^{17,18}$ While these enzymes catalyze a variety of reactions, all characterized thus far use Fld/Fd as an electron donor or acceptor. ${ }^{20-24}$ For example, the electron transferring flavoprotein/butyryl-coenzyme A (Etf-Bcd) bifurcating system uses the electron donor $\mathrm{NADH}\left(E_{\mathrm{m}}=-320 \mathrm{mV}\right)$ to reduce Fld $\left(E_{\mathrm{m}}^{\mathrm{Sq} / \mathrm{Hq}}=-430 \mathrm{mV}\right)$ or $\mathrm{Fd}\left(E_{\mathrm{m}}=-405 \mathrm{mV}\right)$. This thermodynamically unfavorable reaction is achieved by coupling it to an exergonic one, in this case, the reduction of crotonyl-CoA $\left(E_{\mathrm{m}}=-10 \mathrm{mV}\right) \cdot{ }^{1,22,23}$ The bifurcation of electrons to both a high- and a low-potential acceptor results in an overall thermodynamically favorable reaction. ${ }^{17,22,23,25}$

Homologues of bifurcating electron transfer flavoproteins (Etfs), known as FixAB, have been found in physiologically and phylogenetically distinct nitrogen-fixing organisms such as Azotobacter vinelandii, ${ }^{26,27}$ Rhodopseudomonas palustris, ${ }^{28}$ Rhodospirillum rubrum, ${ }^{29}$ and Sinorhizobium meliloti. ${ }^{30,31}$ Previous studies demonstrated that disrupting the Fix system in R. palustris, $R h$. rubrum, and S. meliloti completely abolishes or significantly impairs their ability to grow under nitrogen fixing conditions, suggesting that Fix may serve as a source of electrons to nitrogenase. $^{28-30}$ Given the homology between FixAB and known bifurcating Etfs, it was hypothesized that the Fix system uses electron bifurcation to generate low-potential reducing equivalents for nitrogenase. ${ }^{20}$

While the FixABCX complex is clearly linked to nitrogen fixation in many diazotrophs, its specific role has not been firmly established, nor has its ability to generate a reductant for nitrogenase via electron bifurcation been demonstrated. Here, we report electron bifurcation by the FixABCX complex from the obligate aerobe $A$. vinelandii and characterize the Fix proteins using advanced biochemical and spectroscopic tools. In addition, we provide evidence that FixABCX provides electrons for nitrogenase in $A$. vinelandii cells. Overall, this work establishes a new pathway for the generation of a low-potential reductant required by nitrogenase and elucidates a mechanism by which biology can overcome thermodynamic barriers to accomplish a difficult reductive reaction.

\section{MATERIALS AND METHODS}

Construction of an $A$. vinelandii $\Delta$ fix Mutant. A. vinelandii strain DJ was the wild type strain used for physiological studies and mutant construction. Strains UW195 ( $\Delta r n f 1)$ and UW207 ( $\Delta r n f 2)$ were kindly donated by L. Rubio. ${ }^{32}$ The $\Delta f i x$ mutant was generated by gene disruption with an antibiotic resistance cassette as shown in Figure S1 using primers in Table S1. Briefly, two $1.2 \mathrm{~kb}$ DNA fragments that included $0.3 \mathrm{~kb}$ of fixA (Avin_10520) and $0.1 \mathrm{~kb}$ of $f i x C$ (Avin_10540) were obtained by polymerase chain reaction (PCR) and cloned sequentially in the pT7-7 ampicillin resistant vector using $\mathrm{NdeI} / \mathrm{BamHI}$ and BamHI/HindIII as restriction cloning sites. The kanamycin resistance $\left(\mathrm{Km}^{\mathrm{R}}\right)$ gene $(a p h)$ was isolated as a $1.5 \mathrm{~kb}$ Bam HI fragment from mini-Tn $5^{33}$ and inserted between the $1.2 \mathrm{~kb}$ upstream and downstream regions previously cloned in the pT7-7 vector using the Bam HI restriction cloning site. The final construct was transformed into $A$. vinelandii strain $\mathrm{DJ}$ as described previously. ${ }^{34,35} \mathrm{Km}^{\mathrm{R}}$ transformants were screened for sensitivity to ampicillin $\left(\mathrm{Amp}^{\mathrm{S}}\right) ; \mathrm{Amp}^{\mathrm{S}}$ derivatives were assumed to have arisen from a double-crossover recombination event in which the wild type fixABC genes were replaced by the aph-containing cassette (Figure S1). This replacement was confirmed by PCR and sequencing (Figure S1, and Table S1). Burk's medium ${ }^{36}$ with no nitrogen source or supplemented with ammonium acetate $(1 \mathrm{~g} / \mathrm{L})$ was used for physiological analyses of $A$. vinelandii $\mathrm{DJ}$ and $\Delta r n f$ and $\Delta f i x$ mutants.

Homologous Overexpression of FixABCX. The fix genes of $A$. vinelandii were homologously overexpressed by being placed under control of the nif $H$ promoter, which is used for the transcription of genes associated with the molybdenumdependent nitrogenase (Figure S2). The $4.3 \mathrm{~kb}$ fix operon, which includes six genes (fixfd, Avin_10510; fixA, Avin_10520; fixB, Avin_10530; fixC, Avin_10540; fixX, Avin_10550; ORF6, Avin_10560) (Figure S2), was amplified via PCR using primers specified in Table S2. The PCR product was digested with $\mathrm{XbaI}$ and $B a m H I$ and inserted into a slightly modified pUC19 vector for blue-white screening. Using NdeI and BamHI restriction sites, the fix genes were then cloned into a vector built specifically to support the insertion of genes behind the nif $H$ promoter. ${ }^{37}$ The $f$ ix operon was inserted between two segments of DNA from the nif region of $A$. vinelandii. The flanking regions served as sites for homologous recombination within the chromosome, allowing replacement of nifHD with fix genes (Figure S2). The presence of a streptomycin resistance gene $\left(\mathrm{Sm}^{\mathrm{R}}\right)$ between the flanking regions provided a selectable marker upon transformation of the plasmid into A. vinelandii. ${ }^{34}$ The proper insertion of the fix genes into the final plasmid and the chromosome of $A$. vinelandii were confirmed by PCR and sequencing (Table S2).

Growth of Recombinant $A$. vinelandii and Purification of the FixABCX Complex. Recombinant $A$. vinelandii was grown in a $100 \mathrm{~L}$ fermenter (BioFlo 610, New Brunswick, Hauppauge, NY) at Utah State University's Synthetic Biomanufacturing Institute. Cells were grown in Burk's medium supplemented with $10 \mathrm{mM}$ urea as a nitrogen source. ${ }^{36}$ In the presence of urea, the nif $H$ promoter is repressed. When the cells reached an $\mathrm{OD}_{600}$ of $\sim 1.8$, they were harvested in a stacked disk centrifuge (TSE 10, GEA Westfalia, Northvale, NJ) at $14200 g$ and resuspended in Burk's medium with no source of fixed nitrogen. Upon removal of the fixed nitrogen source, the nif $H$ 
promoter is derepressed and gene expression occurs. A. vinelandii was derepressed for $5 \mathrm{~h}$ to achieve optimal expression of Fix proteins. Because nif genes were replaced with fix genes, Fix rather than nitrogenase was expressed. Following the derepression, cells were harvested and stored at $-80^{\circ} \mathrm{C}$ until further use. Fermenter conditions were maintained as follows throughout the

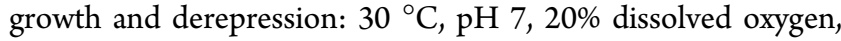
and agitation at $\sim 200 \mathrm{rpm}$.

All purification steps were performed anaerobically under an argon atmosphere. One hundred grams of wet cell paste was resuspended in $50 \mathrm{mM}$ HEPES $(\mathrm{pH} 8), 150 \mathrm{mM} \mathrm{NaCl}, 1 \mathrm{mM}$ dithiothreitol (DTT), and $2 \mathrm{mg}$ of DNase at a cell:buffer ratio of 1:5. Flavin adenine dinucleotide (FAD) $(0.25 \mathrm{mM})$ was also added to the lysis buffer as it increased the flavin cofactor occupancy of the Fix complex. Lysis was achieved with a French pressure cell (SLM Aminco FA-078, Aminco, Rochester, NY) at $200 \mathrm{MPa}$. The cell extract was centrifuged at $8000 \mathrm{~g}$ for $15 \mathrm{~min}$ to remove cell debris. A second centrifugation was then conducted at $50000 \mathrm{~g}$ for $2 \mathrm{~h}$ to obtain the cell membrane fraction. The membranes were solubilized for $1 \mathrm{~h}$ at $4{ }^{\circ} \mathrm{C}$ in $50 \mathrm{mM}$ HEPES ( $\mathrm{pH} 8$ ), $150 \mathrm{mM} \mathrm{NaCl}, 1 \%$ (w/v) $n$-dodecyl $\beta$-D-maltoside (DDM), and $1 \mathrm{mM} \mathrm{DTT}$ at a pellet:buffer ratio of approximately $1: 6$. The solubilized membrane was obtained by centrifugation at $50000 \mathrm{~g}$ for $1 \mathrm{~h}$ and then diluted 3-fold in buffer A [50 mM HEPES ( $\mathrm{pH} 8), 0.02 \%(\mathrm{w} / \mathrm{v})$ DDM, and $1 \mathrm{mM} \mathrm{DTT}$ ] to reduce the salt and detergent concentration before being loaded onto a $100 \mathrm{~mL}$ Q-Sepharose column. The Q-Sepharose column was prewashed with 2 column volumes of buffer $\mathrm{B}$ [50 mM HEPES ( $\mathrm{pH} 8$ ), $1 \mathrm{M} \mathrm{NaCl}, 0.02 \%(\mathrm{w} / \mathrm{v}) \mathrm{DDM}$, and $1 \mathrm{mM} \mathrm{DTT}]$ and then equilibrated with 2 column volumes of buffer A. Once the protein was loaded, unbound proteins were removed with 2 column volumes of buffer $A$, followed by elution of bound proteins with a salt gradient from 15 to $60 \%$ ( 5 column volumes). FixABCX eluted between 32 and $36 \% \mathrm{NaCl}$. Fractions were pooled and diluted to $<100 \mathrm{mM} \mathrm{NaCl}$ for concentration on a $15 \mathrm{~mL}$ Q-Sepharose column prewashed and equilibrated as described above. After loading, the column was washed with 2 column volumes of buffer $\mathrm{A}$ and bound protein eluted with $500 \mathrm{mM} \mathrm{NaCl}$. The resultant concentrated fraction was loaded onto a Sephacryl S-200 column equilibrated with $50 \mathrm{mM}$ HEPES ( $\mathrm{pH} 8), 150 \mathrm{mM} \mathrm{NaCl}, 0.02 \%$ (w/v) DDM, and $1 \mathrm{mM} \mathrm{DTT}$. Fractions containing FixABCX were pooled and concentrated using an Amicon (EMD Millipore, Billerica, MA) concentrator with a $100 \mathrm{kDa}$ cutoff membrane and stored in liquid nitrogen. The purity of FixABCX was determined using sodium dodecyl sulfate-polyacrylamide gel electrophoresis (SDS-PAGE), and the protein concentration was measured using the DC Protein Assay (Bio-Rad, Hercules, CA).

Heterologous Overexpression and Purification of R. palustris FixAB. R. palustris FixAB was co-expressed in Escherichia coli strain NiCo21(DE3) (New England Biolabs, Ipswich, MA) transformed with plasmids based on pMCSG28 and pMCSG21 (DNASU Plasmid Repository, Arizona State University, Tempe, AZ) modified to carry the fixA gene with a $\mathrm{C}$-terminal His tag and the $f i x B$ gene with an $\mathrm{N}$-terminal His tag, respectively. Cells were grown in terrific broth (TB) supplemented with riboflavin $(20 \mathrm{mg} / \mathrm{L})$ and $\mathrm{MgSO}_{4}(2 \mathrm{mM})$ along with carbenicillin $(100 \mu \mathrm{g} / \mathrm{mL})$ and spectinomycin $(100$ $\mu \mathrm{g} / \mathrm{mL}$ ) at $37^{\circ} \mathrm{C}$ while being shaken at $200 \mathrm{rpm}$ to an $\mathrm{OD}_{600}$ of $\sim 2$. After the culture had been fully cooled to $18-20^{\circ} \mathrm{C}$, fix gene expression was induced with $\beta$-D-1-thiogalactopyranoside (IPTG) $(0.1 \mathrm{mM})$ and cells were grown for an additional $12 \mathrm{~h}$ at this lower temperature. Cells were harvested by centrifugation at $11900 \mathrm{~g}$ and $4{ }^{\circ} \mathrm{C}$ for $6 \mathrm{~min}$, and the pellet was stored at $-80^{\circ} \mathrm{C}$.

The cell pellet was suspended in BugBuster $(80 \mathrm{~mL})$ (EMD Millipore) containing 4-(2-aminoethyl)benzenesulfonyl fluoride hydrochloride (AEBSF) (1 mM), tris (2-carboxyethyl)phosphine hydrochloride (TCEP) (1 $\mathrm{mM})$, FAD $(1 \mathrm{mM})$, benzonase nuclease $(20 \mu \mathrm{L})$, and rLysozyme $(2 \mu \mathrm{L})$ (EMD Millipore) and further incubated at $4{ }^{\circ} \mathrm{C}$ for $2 \mathrm{~h}$ while being stirred. After centrifugation at $20000 \mathrm{~g}$ for $30 \mathrm{~min}$ at $4{ }^{\circ} \mathrm{C}$, the supernatant was filtered through a $0.22 \mu \mathrm{m}$ syringe filter. The resulting protein solution was mixed with $3 \mathrm{~mL}$ of pre-equilibrated Ni-NTA resin and incubated overnight at $4{ }^{\circ} \mathrm{C}$ while being stirred. The next day, the mixture was transferred to a column at $4{ }^{\circ} \mathrm{C}$. After the flow-through had been collected, the column was washed with TPGT buffer [20 mM Tris ( $\mathrm{pH} 7.8$ ), $500 \mathrm{mM} \mathrm{KCl,} \mathrm{10 \%} \mathrm{(w/v)}$ glycerol, and $1 \mathrm{mM}$ TCEP] containing successively 20,40 , and $50 \mathrm{mM}$ imidazole in sequence using 20,2 , and 2 column volumes for each, respectively. Finally, the column was developed with 2 column volumes of TPGT buffer containing $100 \mathrm{mM}$ imidazole, and the eluate was collected in different fractions. After SDSPAGE analysis, imidazole was removed from the pooled pure fractions by passage over a 10DG column (Bio-Rad) equilibrated with BPGT buffer [20 mM Bis-Tris propane ( $\mathrm{pH} 9.0), 200 \mathrm{mM}$ $\mathrm{KCl}, 10 \%(\mathrm{w} / \mathrm{v})$ glycerol, and $1 \mathrm{mM} \mathrm{TCEP}]$. Any apo-flavin sites were then reconstituted by overnight incubation of the protein in $1 \mathrm{mM} \mathrm{FAD}$ at $4{ }^{\circ} \mathrm{C}$. Excess flavin was removed by gel filtration on a 10DG column (see above) prior to prompt use or flash freezing in liquid nitrogen and storage at $-80^{\circ} \mathrm{C}$.

Heterologous Overexpression and Purification of Roseiflexus castenholzii FixX. Ro. castenholzii FixX was overexpressed in E. coli using a pCDFDuet-1 vector modified to include a C-terminal strep tag. Transformed cells were grown in Luria-Bertani (LB) broth containing streptomycin $(50 \mu \mathrm{g} / \mathrm{mL})$ at $37{ }^{\circ} \mathrm{C}$ and $250 \mathrm{rpm}$ to an $\mathrm{OD}_{600}$ of $0.4-0.5$. To induce expression of the fixX gene, IPTG $(1.5 \mathrm{mM})$ was added to the cell culture. Ammonium Fe(III) citrate (4 mM), L-cysteine $(2 \mathrm{mM})$, and sodium fumarate $(10 \mathrm{mM})$ were also added. Ammonium $\mathrm{Fe}$ (III) citrate and cysteine increased iron-sulfur cluster occupancy, and sodium fumarate served as an electron acceptor during anaerobic metabolism. The flasks were sealed with rubber stoppers containing cannulas sparging argon into the cell suspension and fixed with exhaust tubes flowing into a water trap. Cells were incubated for $4-6 \mathrm{~h}$ at room temperature and then anaerobically transferred to centrifugation bottles in a Coy chamber (Coy Laboratories, Grass Lake, MI) under a nitrogen atmosphere. Cells were harvested at $5000 \mathrm{~g}$ for $10 \mathrm{~min}$.

All purification steps were performed anaerobically under a nitrogen or argon atmosphere. Wet cell pellets were suspended in lysis buffer [ $50 \mathrm{mM}$ Tris- $\mathrm{HCl}(\mathrm{pH} 8), 150 \mathrm{mM} \mathrm{NaCl}, 1 \mathrm{mM}$ sodium dithionite (Na-dithionite), 5\% glycerol, $1 \mu \mathrm{L} / \mathrm{mL}$ supernatant of a supersaturated phenylmethanesulfonyl fluoride (PMSF) solution, $1 \mathrm{mg} / 10 \mathrm{~mL}$ DNase, and $5 \mathrm{mg} / 10 \mathrm{~mL}$ lysozyme] at a cell:buffer ratio of 1:5. Cells were lysed using a cell bomb (Parr Bomb Instrument Co., Moline, IL) by slowly increasing the pressure to 1500 psi and equilibrating for $30 \mathrm{~min}$ before collecting the lysate. This process was repeated and the supernatant collected by centrifugation at $18000 \mathrm{~g}$ for $20 \mathrm{~min}$. FixX was purified using a single-step affinity column purification using Strep-Tactin Superflow Plus (Qiagen, Hilden, Germany) resin pre-equilibrated with wash buffer containing $50 \mathrm{mM}$ Tris- $\mathrm{HCl}$ (pH 8), $150 \mathrm{mM} \mathrm{NaCl}$, and $1 \mathrm{mM} \mathrm{Na}$-dithionite. Once the protein was loaded, the column was washed until the baseline 
absorbance returned. The protein was then eluted with $50 \mathrm{mM}$ Tris- $\mathrm{HCl}(\mathrm{pH} 8), 150 \mathrm{mM} \mathrm{NaCl}, 1 \mathrm{mM} \mathrm{Na}$-dithionite, and $2.5 \mathrm{mM}$ D-desthiobiotin as a brown band and anaerobically concentrated using an Amicon (EMD Millipore) centrifugal filter with a membrane molecular mass cutoff of $10 \mathrm{kDa}$. The concentrated protein was flash frozen with liquid nitrogen for further analysis.

Heterologous Overexpression and Purification of $\boldsymbol{R} \boldsymbol{h}$. rubrum FixAB. FixAB from Rh. rubrum was overexpressed and purified as described previously. ${ }^{26}$ Briefly, E. coli BL21 cells containing plasmid pET101/d-TOPO::fix $A B^{26}$ were cultured anaerobically in LB broth supplemented with $2.8 \mathrm{mM}$ glucose, $17 \mathrm{mM} \mathrm{KH}_{2} \mathrm{PO}_{4}, 72 \mathrm{mM} \mathrm{K}_{2} \mathrm{HPO}_{4}$, and $15 \mathrm{mg} / \mathrm{L}$ riboflavin at $20{ }^{\circ} \mathrm{C}$ until the early exponential growth phase was reached. At this point, gene expression was induced via the addition of $0.5 \mathrm{mM}$ IPTG, and cells were cultured under the same conditions for an additional $12 \mathrm{~h}$. Harvested cells were resuspended in degassed lysis buffer [20 mM Tris- $\mathrm{HCl}$ ( $\mathrm{pH} 7.6), 10 \mathrm{mM}$ imidazole, $500 \mathrm{mM} \mathrm{NaCl}, 5 \mathrm{mg} / \mathrm{mL}$ lysozyme, and $1 \mathrm{mg} / \mathrm{mL}$ Dnase I] and submitted to three freeze-thaw cycles. The lysate was added to a nickel-NTA column (Qiagen) that had been equilibrated with degassed lysis buffer. The column was washed with degassed lysis buffer, and FixAB was eluted into anaerobic vials using a 10 to $300 \mathrm{mM}$ imidazole gradient in degassed $20 \mathrm{mM}$ Tris- $\mathrm{HCl}(\mathrm{pH} 7.6)$ and $500 \mathrm{mM} \mathrm{NaCl}$. Yellow fractions indicating the presence of FixAB were subjected to buffer exchange using a PD-10 column (GE-Healthcare, Little Chalfont, U.K.) and stored in desalting buffer $[20 \mathrm{mM}$ Tris- $\mathrm{HCl}(\mathrm{pH} \mathrm{7.6)}$ and $100 \mathrm{mM} \mathrm{NaCl}$. Purified FixAB was incubated overnight at $4{ }^{\circ} \mathrm{C}$ with $1 \mathrm{mM} \mathrm{FAD}$ in desalting buffer to reconstitute $\mathrm{FAD}$ cofactors lost during purification. ${ }^{38,39}$ Unbound FAD was rinsed by concentrating the samples with an Amicon membrane (cutoff $30 \mathrm{kDa}$ ) followed by dilution with desalting buffer containing $0.5 \mu \mathrm{M}$ FAD. Reconstituted samples were stored at $-20^{\circ} \mathrm{C}$. The purity and identity of the fractions were assessed via SDS-PAGE and mass spectrometry, respectively.

Dynamic Light Scattering. Dynamic light scattering (DLS) was performed on a DynaPro NanoStar (Wyatt Technology, Santa Barbara, CA) to determine the size distribution and hydrodynamic radii of species in solution. Samples were filtered through a $0.1 \mu \mathrm{m}$ syringe filter prior to the experiments. DLS was measured aerobically using $10 \mu \mathrm{L}$ of buffer as the control and also $1 \mathrm{mg} / \mathrm{mL}$ enzyme using a disposable cyclic olefin copolymer cuvette at $25^{\circ} \mathrm{C}$.

Protein Identification, Chemical Cross-Linking, and Model Construction. Identification of protein from gel bands and solution digestion was performed according to standard protocols recommended by the manufacturers using a trypsin (Promega, Madison, WI) protease:complex ratio of 1:50 to 1:100 overnight and pepsin (Sigma, St. Louis, MO) protease:complex ratio of $1: 10$ for $60 \mathrm{~s}$. Proteins were identified as described previously ${ }^{5}$ using a maXis Impact UHR-QTOF instrument (Bruker Daltonics, Billerica, MA) interfaced with a Dionex 3000 nano-uHPLC instrument (Thermo-Fisher, Waltham, MA) followed by data analysis in Peptide Shaker. ${ }^{40}$ Chemical cross-linking was performed using $20 \mu \mathrm{g}$ of the FixABCX complex and $1 \mathrm{mM}$ bis(sulfosuccinimidyl)suberate (BS3) (Thermo-Fisher) in $50 \mathrm{mM}$ HEPES ( $\mathrm{pH} 7.2$ ), $150 \mathrm{mM}$ $\mathrm{NaCl}$ buffer at room temperature for $1 \mathrm{~h}$. The reaction was quenched by addition of $120 \mathrm{mM}$ Tris (final concentration). The resulting mixture was separated by SDS-PAGE ( 4 to $20 \%$ linear gradient gel, Bio-Rad) and stained with Coomassie Brilliant Blue
(Thermo-Fisher). Protein bands of interest were excised from the gel and digested with trypsin as described above. For crosslink mapping, a Spectrum Identification Machine (SIM) was used. ${ }^{41}$ Precursor and fragment ion tolerances were set to $\pm 20 \mathrm{ppm}$. Intact protein analysis was performed as described previously using a Bruker Micro-TOF mass spectrometer (Bruker Daltonics). ${ }^{42}$ Noncovalent mass spectrometry experiments were conducted on a SYNAPT G2-Si instrument (Waters, Milford, MA) in a fashion similar to that described previously. ${ }^{43}$ Briefly, the FixABCX complex sample was buffer exchanged to $200 \mathrm{mM}$ ammonium acetate ( $\mathrm{pH} \mathrm{7}$ ) (Sigma) using $3 \mathrm{kDa}$ molecular mass cutoff spin filters (Pall Corp., Port Washington, NY) and infused from in-house prepared gold-coated borosilicate glass capillaries to the electrospray source at a protein concentration of $2-3 \mu \mathrm{M}$ and a rate of $\sim 90 \mathrm{~nL} / \mathrm{min}$. The instrument was tuned to enhance performance in the high mass-to-charge range. The following settings were used: source temperature, $30{ }^{\circ} \mathrm{C}$; capillary voltage, $1.7 \mathrm{kV}$; trap bias voltage, $16 \mathrm{~V}$; argon flow in the collision cell (trap), $7 \mathrm{~mL} / \mathrm{min}$. The transfer collision energy was held at $10 \mathrm{~V}$, while the trap energy varied between 10 and $200 \mathrm{~V}$. Data analysis was performed in MassLynx version 4.1 (Waters).

Protein homology models were generated by Phyre2, ${ }^{44}$ and energy-minimized models were docked using ClusPro2 with restrictions derived from chemical cross-linking experiments. ${ }^{45-48}$ The flavin and iron-sulfur cluster cofactors were added using SwissDock ${ }^{49,50}$ for individual subunits and eventually added as rigid bodies to the final FixABCX complex model. Molecular graphics were created using the UCSF Chimera package. ${ }^{51}$

Electron Paramagnetic Resonance Spectroscopy. Electron paramagnetic resonance (EPR) spectra were recorded with a Bruker E-500 spectrometer (X-band, $9.38 \mathrm{Ghz}$ ) equipped with a SHQ resonator (Bruker), an in-cavity cryogen free VT system (ColdEdge Technologies, Allentown, PA), and a MercuryiTC temperature controller (Oxford Instruments, Abingdon, U.K.). Spin quantifications were performed by double integration of the spectra after manual baseline subtraction in the OriginPro software package and referenced to copper-triethylamine standards $(75-125 \mu \mathrm{M})$ measured under the same conditions. To assist with spectral deconvolution and assignment of $g$ factors $( \pm 0.003)$, computer simulations of the experimental spectra were performed in MatLab using the EasySpin package and "esfit" fitting function incorporating $g$ strain to replicate line broadening.

Electron Bifurcation Assays. FixABCX electron bifurcation activity was measured anaerobically in an ultraviolet-visible (UV-vis) spectrophotometer (Varian Cary 50 Bio, Agilent Technologies, Santa Clara, CA) using quartz cuvettes $(d=1 \mathrm{~cm})$. All assays were carried out in 50 mM HEPES ( $\mathrm{pH} 7.5$ ), $10 \%$ glycerol, and $0.02 \% \mathrm{DDM}$ and contained the following: $0.8 \mu \mathrm{M}$ FixABCX (1.7 nmol of flavin/nmol of FixABCX and $9.1 \mathrm{nmol}$ of $\mathrm{Fe} / \mathrm{nmol}$ of FixABCX), $85 \mu \mathrm{M} \mathrm{Fld}^{\mathrm{Sq}}, 200 \mu \mathrm{M} \mathrm{NADH}$, and $300 \mu \mathrm{M}$ coenzyme $\mathrm{Q}_{1}\left(\mathrm{CoQ}_{1}\right) . \mathrm{NADH}$, Fld $^{\mathrm{Sq}}$, and Fld ${ }^{\mathrm{Ox}}$ were monitored at $340 \mathrm{~nm}\left(\varepsilon=6.2 \mathrm{mM}^{-1} \mathrm{~cm}^{-1}\right), 580 \mathrm{~nm}$ $\left(\varepsilon=5.7 \mathrm{mM}^{-1} \mathrm{~cm}^{-1}\right)$, and $450 \mathrm{~nm}\left(\varepsilon=11.3 \mathrm{mM}^{-1} \mathrm{~cm}^{-1}\right)$, respectively. ${ }^{12,52}$ The Fld used in the assays as the low-potential electron acceptor was purified in the hydroquinone state as previously described. ${ }^{5} \mathrm{Fld}^{\mathrm{Hq}}$ was exposed to oxygen for a short period of time, upon which the majority $(>80 \%)$ of the $\mathrm{Fld}^{\mathrm{Hq}}$ converted to the semiquinone form. The protein was then degassed with argon, and the absorbance of the semiquinone 
species was measured at $580 \mathrm{~nm}$. The concentration was then calculated using the extinction coefficient $\left(\varepsilon=5.7 \mathrm{mM}^{-1} \mathrm{~cm}^{-1}\right)$.

Thermodynamic Calculations. Standard reduction midpoint potentials of the $\mathrm{NAD}^{+} / \mathrm{NADH}\left(E_{\mathrm{m}}=-320 \mathrm{mV}\right)$, $\mathrm{CoQ} / \mathrm{CoQH}_{2}\left(E_{\mathrm{m}}=10 \mathrm{mV}\right), \mathrm{Fld}^{\mathrm{Ox} / \mathrm{Sq}}\left(E_{\mathrm{m}}=-180 \mathrm{mV}\right)$, and $\mathrm{Fld}^{\mathrm{Sq} / \mathrm{Hq}}\left(E_{\mathrm{m}}=-460 \mathrm{mV}\right)$ half-reactions were converted to standard Gibbs free energies $\left(\Delta G^{\circ \prime}\right)$ with the equation

$$
\Delta G^{\circ \prime}=-n F E^{\circ \prime}
$$

where $n$ is the number of electrons (moles) and $F$ is the Faraday constant $\left(96485.34 \mathrm{~J} \mathrm{~V}^{-1} \mathrm{~mol}^{-1}\right)$ (Table S5). The standard Gibbs free energy of reaction $\left(\Delta G_{\mathrm{rxn}}^{\circ \prime}\right.$, in joules per mole) can be calculated for the reaction of interest using the equation

$$
\Delta G_{\mathrm{rxn}}^{\mathrm{o}^{\prime}}=\sum\left|v_{\mathrm{i}}\right| \Delta G_{(\text {products })}^{\mathrm{o}^{\prime}}-\sum\left|v_{\mathrm{i}}\right| \Delta G_{(\text {reactants })}^{\mathrm{o}^{\prime}}
$$

where $\left|v_{\mathrm{i}}\right|$ is the stoichiometric coefficient, $\mathrm{i}$ is the product or reactant, and $\Delta G_{(\text {products) }}^{\circ \prime}$ and $\Delta G_{(\text {reactants })}^{\circ}$ are the standard Gibbs free energy of the products and reactants (joules per mol), respectively, calculated from eq 2 .

Transient Absorption Spectroscopy. The ultrafast (100 fs to $5.1 \mathrm{~ns}$ ) transient absorption spectroscopy (TAS) spectrometer employed in this study uses an amplified 4W Ti:sapphire laser (Libra, Coherent, $800 \mathrm{~nm}, 1 \mathrm{kHz}, 100 \mathrm{fs}$ pulse width) and the Helios spectrometer (Ultrafast Systems LLC, Sarasota, FL). A fraction of the $800 \mathrm{~nm}$ Libra output was frequency-doubled in beta barium borate (BBO) to produce the desired pump wavelength (480 $\mathrm{nm}$ for the data described here) for sample excitation, which was then directed into the Helios. The pump pulses were passed through a depolarizer and chopped by a synchronized chopper to $500 \mathrm{~Hz}$ before reaching the sample. The pump pulse energy was $1.1 \mu \mathrm{J} /$ pulse at the sample. Another fraction of the $800 \mathrm{~nm}$ Libra output was guided directly into the Helios for generation of the probe. Within the spectrometer, a white light continuum of wavelengths including 340-800 nm was generated using a $2 \mathrm{~mm}$ thick $\mathrm{CaF}_{2}$ crystal. This beam was split into a probe beam and a reference beam. The probe beam was focused into the sample where it was overlapped with the pump beam. The transmitted probe and reference beams were then focused into optical fibers coupled to multichannel spectrometers with CMOS sensors with $1 \mathrm{kHz}$ detection rates. The reference signal is used to correct the probe signal for pulse-to-pulse fluctuations in the white light continuum. The time delay between the pump and probe pulses was controlled by a motorized delay stage. For all transient absorption measurements, the sample was made in an Mbraun glovebox $\left(\mathrm{N}_{2}\right.$ atmosphere), sealed in a $2 \mathrm{~mm}$ quartz cuvette, and constantly stirred to prevent photodegradation. Rh. rubrum FixAB and $A$. vinelandii FixABCX concentrations were approximately 150 and $43 \mu \mathrm{M}$, respectively, and they were measured in their as-isolated state (mostly oxidized). The $R h$. rubrum dimer contained $>0.7 \mathrm{nmol}$ of flavin/nmol of FixAB, and the $A$. vinelandii FixABCX complex contained $1.7 \mathrm{nmol}$ of flavin/nmol of FixABCX. For the purpose of this study, light initiated the formation of the semiquinone intermediates for each flavin through generation of the $\mathrm{FAD}$ excited state and donation of electrons from nearby protein residues or the other flavins. Qualitatively, this experiment shows which type of semiquinone is formed for a particular FAD site and suggests how thermodynamically stable that intermediate is, based on its lifetime. All experiments were conducted at room temperature. The change in the absorbance signal $(\Delta A)$ was calculated from the intensities of signals detected after sequential probe pulses with and without the pump pulse excitation. Data were collected
(350 pump shots per time point) three consecutive times and then averaged. The experiment was repeated three times for $A$. vinelandii FixABCX and once for Rh. rubrum FixAB. Data were corrected for spectral chirp using SurfaceXplorer (Ultrafast Systems LLC). ASQ signals were fit in Igor Pro with a doubleexponential function. The $550 \mathrm{~nm}$ emissive feature in $\mathrm{Rh}$. rubrum FixAB is due to stimulated emission. ${ }^{53}$

\section{RESULTS AND DISCUSSION}

Effect of fix and rnf Deletions on Nitrogen Fixation in A. vinelandii. To determine whether the Fix system is associated with diazotrophic growth in A. vinelandii, as in $R$. palustris, Rh. rubrum, and $S$. meliloti, ${ }^{28,29,31}$ a deletion mutant lacking fix $A B C$ was generated (Figure $S 1$ ). This mutant, unlike those of R. palustris, Rh. rubrum, and S. meliloti, exhibited equally robust growth on solid media with and without added fixed nitrogen (Figure 1). This nitrogen-fixing $\left(\mathrm{Nif}^{+}\right)$phenotype was also

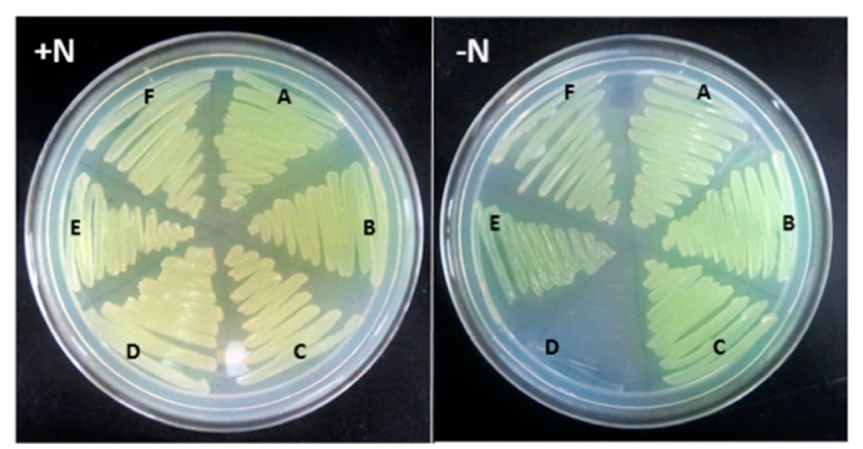

Figure 1. Phenotype of A. vinelandii DJ wild type (A), $\Delta f i x$ (B), $\Delta r n f 1$ (C), $\Delta$ fix $\Delta r n f 1$ (D), $\Delta r n f 2$ (E), and $\Delta f i x \Delta r n f 2$ (F) strains. Wild type and mutant strains were cultivated in Burk's medium supplemented with ammonium acetate $(+\mathrm{N})$ or with no added fixed nitrogen $(-\mathrm{N})$. All samples were grown aerobically.

observed when the $A$. vinelandii fix mutant expressed the vanadium and iron-only alternative nitrogenases or when cultured under low-aeration conditions (data not shown). Although the results appeared to indicate that Fix is not associated with nitrogen fixation in $A$. vinelandii and were consistent with a previous study by Wientjens, ${ }^{27}$ we also tested the possibility of redundancy, ${ }^{54}$ thinking that an alternative complex could participate in balancing the chemical energy and reductant pools in the absence of Fix, masking the effect of the $\triangle$ fixABC mutation.

Rnf (Rhodobacter nitrogen fixation) is a membrane-bound complex found in some diazotrophs that, like Fix, has been hypothesized to generate reductant in the form of Fd or Fld for nitrogen fixation. ${ }^{16,55,56}$ Nitrogen-fixing organisms that have genes encoding Rnf typically do not have genes encoding Fix and vice versa. Interestingly, $A$. vinelandii is one of the few known diazotrophs with genes encoding both complexes. ${ }^{57}$ The physiological implications of having both Rnf and Fix are not altogether clear, but given that $A$. vinelandii fixes nitrogen under highly oxic conditions, the combination of Rnf and Fix could confer the ability to fine-tune the redox status of the cell to a high degree under a wide range of oxygen tensions.

It has been suggested that Rnf uses the energy of the proton motive force to generate reduced $\mathrm{Fd} / \mathrm{Fld}^{15,16}$ while Fix uses electron bifurcation. ${ }^{18,20}$ Neither the Rnf nor Fix complex, however, has previously been directly implicated in the delivery of electrons to nitrogenase. Curatti et al. ${ }^{32}$ showed that 
A. vinelandii possesses two Rnf complexes, Rnfl associated with nitrogen fixation and Rnf2, which is expressed constitutively. $\Delta r n f 1$ mutants, although still able to grow diazotrophically (Figure 1), consistently exhibit a long lag in nif gene expression and diazotrophic growth during derepression studies. ${ }^{32}$ To test whether Rnf and Fix might be compensating for one another, we transformed $\Delta r n f$ mutants of $A$. vinelandii with the $\Delta f i x$ construct (Figure $S 1)^{32}$ to generate double mutants of A. vinelandii lacking either Rnf1 and Fix or Rnf2 and Fix. The $\Delta f i x-\Delta r n f 1$ A. vinelandii strain was able to grow when fixed nitrogen was supplied, but no growth was observed under nitrogen fixing conditions (Figure 1). Therefore, cells lacking both Rnf1 and Fix displayed a non-nitrogen fixing ( $\mathrm{Nif}^{-}$) phenotype. Our data provide support for a role of both Fix and Rnf1 in providing reducing equivalents to nitrogenase and indicate that the two complexes have compensatory activities, such that either one can replace the other to ensure electron flow. Furthermore, this is the first study to link the Fix complex to nitrogen fixation in $A$. vinelandii. The $\Delta f i x-\Delta r n f 2 A$. vinelandii mutant control strain was able to grow with or without added fixed nitrogen (Figure 1), confirming that Rnf1, but not Rnf2, can support nitrogen fixation.
Characterization of the FixABCX Complex. To understand how Fix can support nitrogen fixation, we characterized the FixABCX complex and its activity in vitro. The fix operon of A. vinelandii consists of six genes, fix $\mathrm{Fd}$ (annotated as fix $\mathrm{P}$ in some literature), fix A, fix B, fix C, fix X, and Avin_10560 (designated ORF6) (Figure S2). FixAB is homologous to the previously characterized EtfAB, which is part of the Etf-Bcd bifurcating complex. FixCX is similar to Etf ubiquinone oxidoreductase (Etf-QO), involved in the transfer of electrons to the quinone pool in the membrane. ${ }^{29}$ On the basis of the similarity to other Etf systems, it is hypothesized that the Fix complex oxidizes $\mathrm{NADH}$ and bifurcates one electron to the highpotential quinone pool (exergonic branch) and drives the other electron to a low-potential acceptor in the form of Fd or Fld (endergonic branch) (Figure 2). ${ }^{20}$

Most microbes with fix genes have only fixABCX; homologues $f i x \mathrm{Fd}$ and ORF6 have not been investigated in $f i x$ gene clusters of any other species thus far. ${ }^{27,58}$ Although FixFd and ORF6 were not specifically addressed in this study, it is thought that FixFd, a small iron-sulfur protein, ${ }^{27,59}$ may serve as a low-potential acceptor in Fix electron bifurcation. ORF6 is described as being ferritin-like, but studies of its function have yet to be conducted.

A

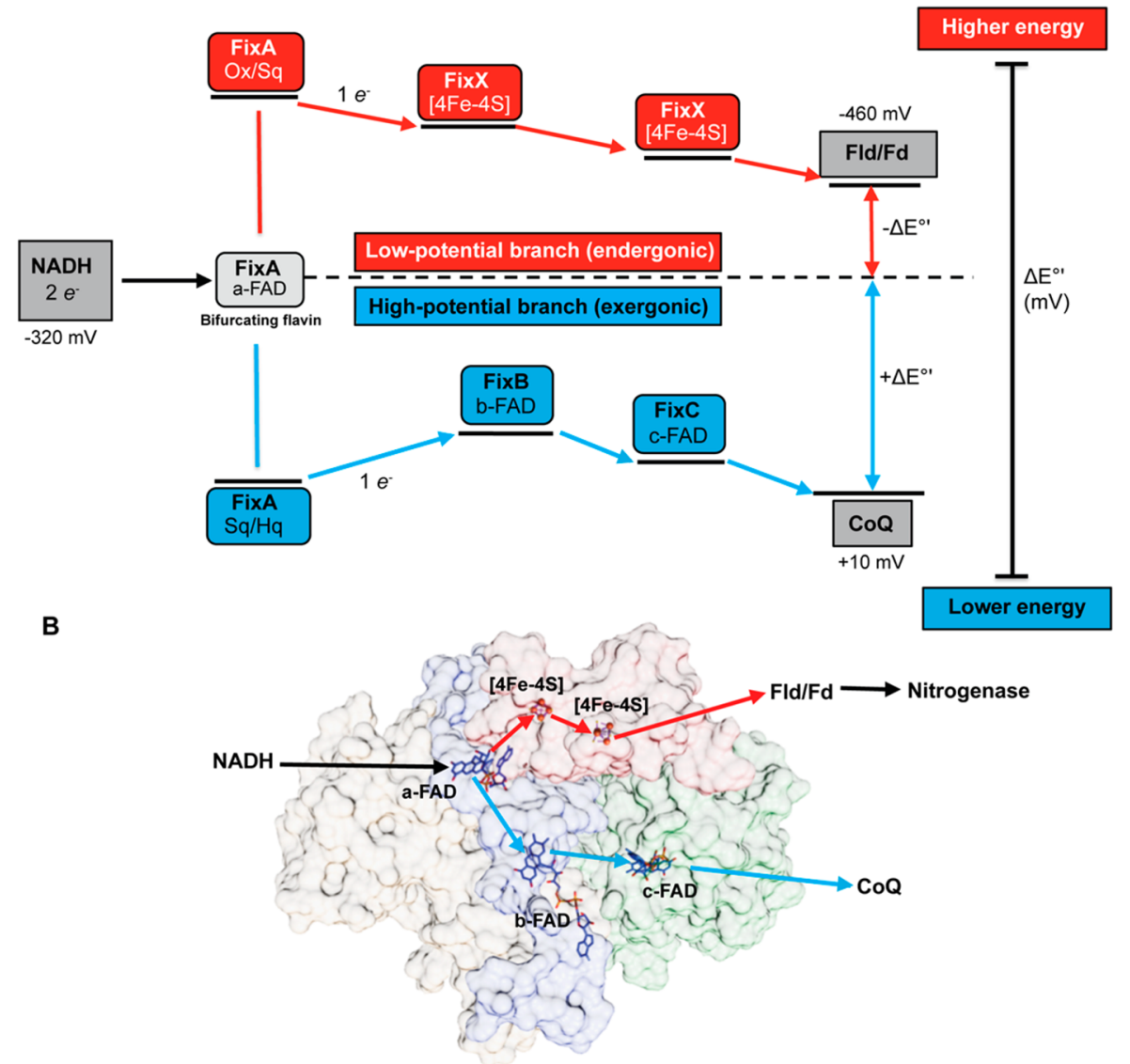

Figure 2. (A) Proposed mechanism of FixABCX electron bifurcation in A. vinelandii, operating within the framework of the known oxidation-reduction potentials of $\mathrm{NADH}, \mathrm{Fld} / \mathrm{Fd}$, and CoQ. It is hypothesized that crossed potentials of the bifurcating flavin (a-FAD) promote electron bifurcation based on the appearance of a short-lived ASQ. Once the first electron transfers into the exergonic branch, the second electron, sitting at a very low reduction potential, is thermodynamically unstable and immediately transfers into the endergonic branch composed of the low-potential iron-sulfur clusters of FixX. The exergonic branch is set up to ensure the delivery of electrons to c-FAD where electrons accumulate before being transferred to CoQ. The specific oxidation-reduction potential levels are qualitative unless otherwise noted. (B) Electron transfer pathways illustrated in the FixABCX structural model generated by docking (ClusPro2) four homology models (Phyre2) (Figure S8). 
The fix genes from $A$. vinelandii were homologously overexpressed under control of the nif $\mathrm{H}$ promoter (Figure S2), which regulates transcription of genes encoding molybdenum nitrogenase. This approach allows gene(s) of interest to be overexpressed upon removal of a fixed nitrogen source. On the basis of the hypothesis that the FixABCX complex delivers one electron per bifurcation reaction to the quinone pool [coenzyme Q (CoQ)], it was anticipated that the enzyme could be associated with the membrane fraction, as observed for Etf-QO. ${ }^{60,61}$ Indeed, a previous study found that heterologously overexpressed $R h$. rubrum FixC was localized to the membrane fraction in E. coli. ${ }^{29}$ Furthermore, an N-terminal lipophilic tail and transmembrane helix were predicted on the FixC subunit based on the amino acid sequence (SACS MEMSAT2 and Phyre 2 prediction software). ${ }^{44,62}$ Attempts to purify the FixABCX complex confirmed membrane association. After a range of $\mathrm{NaCl}$ concentrations $(0-1 \mathrm{M})$ and a variety of non-ionic detergents had been used to solubilize the complex, the detergent $n$-dodecyl $\beta$-D-maltoside (DDM), used for many membrane proteins, ${ }^{61,63}$ was found to be most effective for the isolation of intact FixABCX in a soluble and active form.

Upon extraction of the FixABCX complex from the membrane, the DDM-solubilized fraction was subjected to anion-exchange and size-exclusion chromatography. SDS-PAGE analysis of the purified FixABCX complex revealed four bands corresponding in size to FixA, FixB, FixC, and FixX (Figure 3)

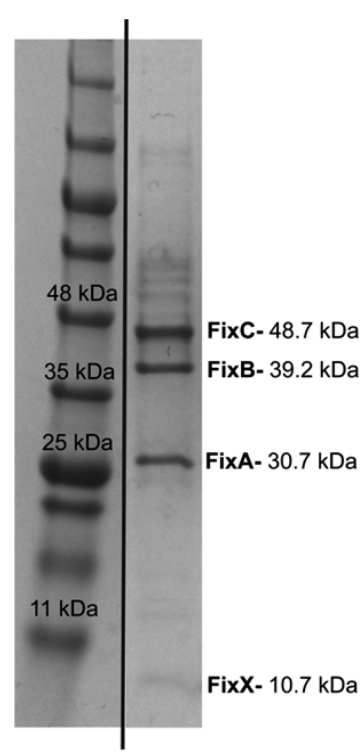

Figure 3. SDS-PAGE gel of the purified $(\sim 80 \%)$ FixABCX complex from $A$. vinelandii (extra lanes were removed). All Fix protein bands were verified by mass spectrometry (Figure S3), and according to densitometry, the subunit stoichiometry of FixABCX is $1: 1: 1: 1$.

and was $>80 \%$ homogeneous [defined by percent band (Image Lab, Bio-Rad)]. Mass spectrometry confirmed the identities of the four Fix subunits (Figure S3), and densitometry of the stained gel indicated that the band intensities were consistent with an A:B:C:X subunit stoichiometry of $1: 1: 1: 1$.

Dynamic Light Scattering (DLS). DLS was used to determine the oligomeric state of the FixABCX complex on the basis of particle size. The complex in buffer containing $0.02 \% \mathrm{DDM}$ displayed an average hydrodynamic radius of $5.1 \pm 0.3 \mathrm{~nm}$, corresponding to an estimated molecular mass of $150 \mathrm{kDa}$ versus the expected mass of $129 \mathrm{kDa}$ for the FixABCX heterotetramer (Figure S4). This slightly larger-than-expected complex is consistent with attachment of DDM to the protein tetramers. While there was also some contribution from larger aggregates, which are very prominent in the DLS output because of their much higher scattering efficiencies $(\approx 12-16 \mathrm{~nm})$, the aggregates comprised $<1 \%$ of the population (Figure S4). Buffer containing DDM was used as a negative control and produced micelles with a radius of $\approx 4.3 \mathrm{~nm}$ (Figure S4). Overall, the DLS data suggest FixABCX exists as individual heterotetramers in solution.

FixABCX Ligand Composition and Structural Model. Multiple electron transfer cofactors, including flavins and ironsulfur clusters, have been identified in electron bifurcating enzyme complexes, with a single flavin proposed to serve as the site of bifurcation. ${ }^{17,18,20,25}$ On the basis of common sequence motifs for ligand binding, FixABCX was predicted to have three FAD moieties, one each in FixA, FixB, and FixC, and two [4Fe-4S] clusters in FixX. Native mass spectrometry (MS) was employed to reveal the subunit stoichiometry and ligand composition of the complex.

All complex members were first identified on the basis of fragments produced by two different proteases, trypsin and pepsin. Additionally, proteolysis reactions revealed that FixABCX and a small amount of Fld (NifF) are purified together. The next step was to determine the molecular masses of the intact proteins. Reverse phase LC-MS confirmed full-length FixA and that FixB and FixC subunits did not contain $\mathrm{N}$-terminal Met residues. The purified FixABCX complex, under anaerobic conditions, was analyzed using native MS conditions by direct infusion on a Synapt G2-Si. Under standard conditions $(60 \mathrm{~V}$ collision energy), the complex dissociated into subcomplexes of FixAB and FixCX. A consistent ion signal for the tetrameric FixABCX complex could not be maintained despite the presence of all four proteins and cofactors in the sample after size-based purification. The FixAB component contained two FAD molecules and closely matched the expected size $(71414.8 \mathrm{Da}$ vs a predicted MW of $71413.7 \mathrm{Da}$ ) (Figure 4A,B), whereas the FixCX subcomplex containing $\mathrm{FAD}$ and two $[4 \mathrm{Fe}-4 \mathrm{~S}]$ clusters was slightly heavier than expected (60310.1 Da vs a predicted MW of 59932.9 Da, FixCX) (Figure 4B). The additional mass of 377.2 Da matches very closely that of riboflavin (Rf) (MW of 376.4 Da), raising the intriguing possibility that it may also be associated with the complex (Figure 4B).

The UV-vis spectrum of FixABCX revealed a distinct peak at $428 \mathrm{~nm}$, as well as oxidized flavin signatures with shoulders near 460 and $365 \mathrm{~nm}$ [Figure 5 (black trace)]. After denaturation of FixABCX and removal of the protein by centrifugation, the soluble fraction demonstrated clear signatures of flavins with broad maxima at 370 and $450 \mathrm{~nm}$ [Figure 5 (red trace)]. The band at $428 \mathrm{~nm}$ is not a usual signature of flavins, and such a band has not been observed in Fix $\mathrm{AB}$ from other diazotrophs that have been expressed in E. coli. Thus, it is likely that this species is associated with FixC or FixX and may be covalently attached to the protein, as it does not remain in the supernatant when denatured protein is removed. The signatures of the $[4 \mathrm{Fe}-4 \mathrm{~S}]$ clusters are not evident in as-purified FixABCX but are not expected to be prominent because of scattering and their broad and relatively weak signals (400-420 nm; $\left.\varepsilon \approx 2-4 \mathrm{mM}^{-1} \mathrm{~cm}^{-1}\right)$. $^{64}$

Once we had established the subunit stoichiometry and ligand composition of the FixABCX complex, we investigated the quaternary interactions that define the active enzyme. Models for each of the Fix subunits were generated using Phyre2, ${ }^{44}$ and the 
A

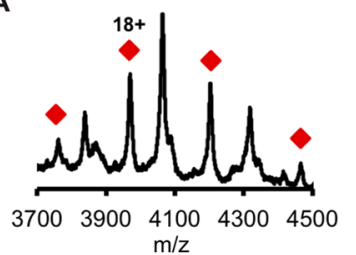

B

\begin{tabular}{llll}
\hline Subcomplex & $\begin{array}{l}\text { Expected } \\
\text { mass (Da) }\end{array}$ & $\begin{array}{l}\text { Empirical } \\
\text { mass (Da) }\end{array}$ & Ligands \\
\hline FixAB & $71,413.7$ & $71,414.8$ & 2 FAD \\
FixCX & $59,932.9$ & $60,310.1$ & $\begin{array}{l}\text { FAD, 2 [4Fe-4S] } \\
+377 \mathrm{Da}\end{array}$ \\
\hline
\end{tabular}
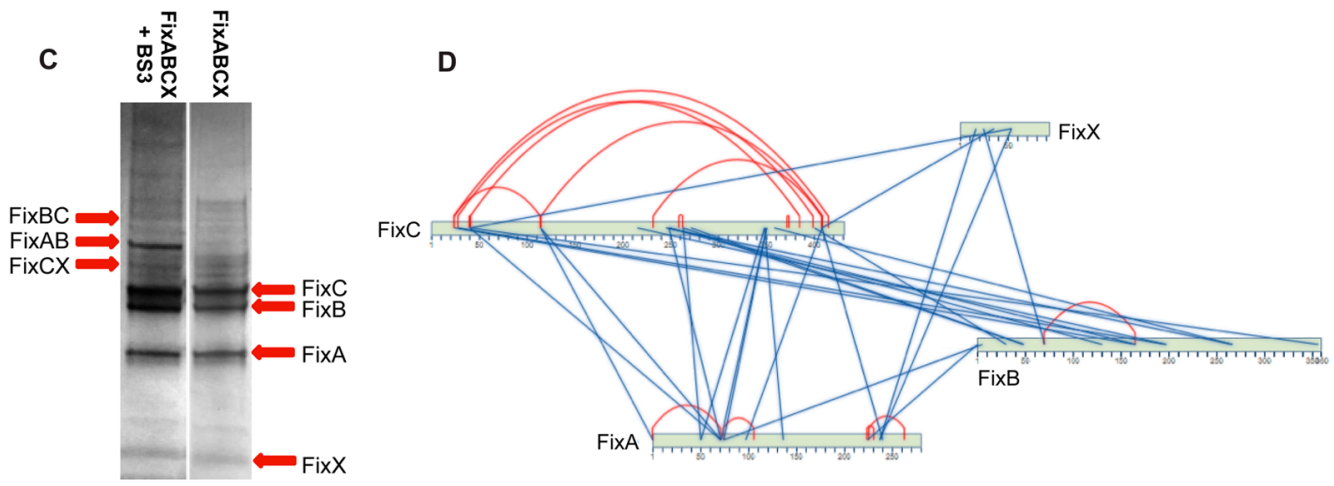

Figure 4. A. vinelandii FixABCX complex composition. (A) Native mass spectrum of FixAB containing two FAD cofactors (71414.8 Da; calculated MW of 71413.7 Da) generated during FixABCX complex activation in the gas phase. Red diamonds signify charge state envelope centered around a charge of +18 . The unmarked masses are the charge state envelope of the molecular chaperone DnaK. (B) Subcomplexes obtained during FixABCX complex activation. (C) SDS-PAGE gel of the FixABCX complex (right) cross-linked with BS3 reagent (left). The most distinguished bands in the cross-linking reaction, migrating around the 60,70 , and $88 \mathrm{kDa}$ molecular weight marker, were identified as FixCX, FixAB, and FixBC dimers, respectively. (D) Protein-protein interaction map based on the highest-scoring cross-links (score of $\geq 7$; red and blue lines indicate intra- and inter-cross-links, respectively). A complete list of generated cross-links can be found in Table S3.

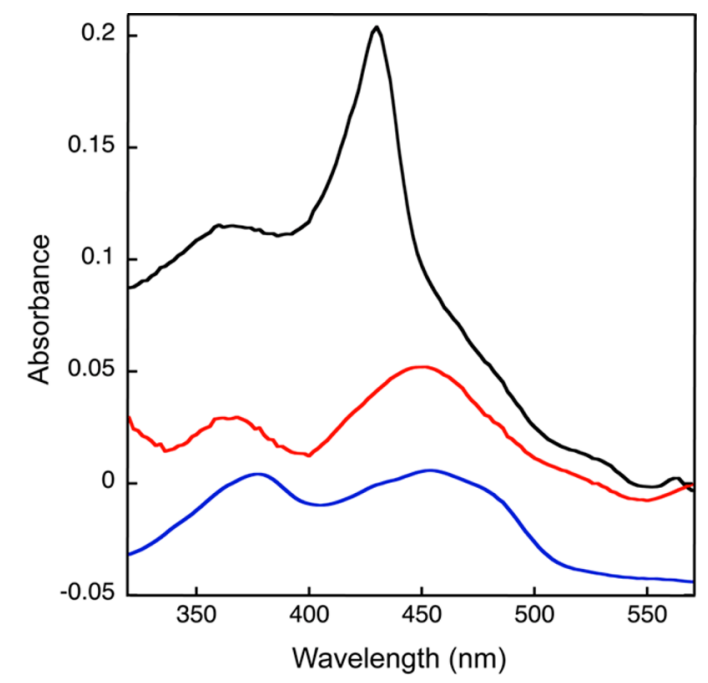

Figure 5. UV-vis spectrum of the FixABCX complex from A. vinelandii demonstrating the presence of flavin: black for as-purified FixABCX, red for cofactors released upon denaturation of FixABCX, and blue for flavins as observed in the spectrum of FixAB from R. palustris, vertically offset by $-0.05 \mathrm{AU}$ for the sake of clarity. The two spectra representing FixABCX were corrected for Raleigh scattering by fitting the baseline to the equation for scattering and then subtracting the fit from the measured spectrum to obtain a corrected spectrum. A. vinelandii FixABCX was prepared in $50 \mathrm{mM}$ Tris- $\mathrm{HCl}(\mathrm{pH} 8), 150 \mathrm{mM} \mathrm{NaCl}$, and $0.02 \%(\mathrm{w} / \mathrm{v})$ DDM. $R$. palustris FixAB was prepared in $20 \mathrm{mM}$ Bis-Tris propane (pH 9), $200 \mathrm{mM} \mathrm{KCl}, 10 \%$ (w/v) glycerol, and $1 \mathrm{mM}$ tris(2-carboxyethyl)phosphine (TCEP).

figures of merit are provided in Figures S5-S8. To validate these subunit models and to elucidate protein-protein interactions within the FixABCX complex, chemical cross-linking was used. The bis(sulfosuccinimidyl)suberate (BS3) cross-linking reagent is homobifunctional, reacting with primary amines and hydroxyl groups to form covalent bonds. Cross-linked samples were separated using one-dimensional SDS-PAGE to confirm connections between subunits and to enrich cross-linked species in samples subsequently analyzed by liquid chromatography tandem mass spectrometry (LC-MS/MS) (Figure 4C and Table S3). Overall, the reaction of the FixABCX complex with BS3 reagent produced more than 200 connections. For initial model building of the FixABCX complex and to confirm the subunit homology models, a reduced set of cross-links of very high confidence were selected (probability score of $>7$; significance is $>3$ ) (Figure 4D).

The resulting model of the quaternary structure provides insightful hypotheses to be tested in the next generation of experiments (Figure 2B and Figure S8E). The MS-based model places the cofactors in locations that suggest a pair of possible paths for electron transfer, both emanating from the flavin in FixA. One provides a plausible route to the [4Fe-4S] clusters in FixX, and the other can provide a path to the site at which quinone is found to be bound in the functional homologue of FixC, the Etf-QO (Figure $2 \mathrm{~B}$ and Figure S8E). ${ }^{65}$ While some of the distances between cofactors are longer than ideal for direct electron transfer, conformational changes could be invoked to bring them sufficiently close ${ }^{22,39,66}$ but we also note that the model places conserved Trp and Tyr in locations that could provide electron transfer paths between cofactors (Figure S8E). ${ }^{67-69}$ Thus, our model provides testable hypotheses for which amino acids are expected to alter complex stability or internal electron transfer upon mutagenesis. These amino acids will be targets of experiments to elucidate fundamental elements of bifurcating activity and test attribution of bifurcating activity to FixABCX.

EPR Spectroscopy. FixABCX was analyzed by low-temperature continuous wave $\mathrm{X}$-band EPR spectroscopy to assess its flavin 
radical content and the identity of iron-sulfur clusters. The EPR spectrum of the as-purified enzyme showed a very weak fast relaxing, broad signal that was strongest near $5 \mathrm{~K}$ along with a weak $g \sim 2$ radical signal (Figure 6 and Table S4).

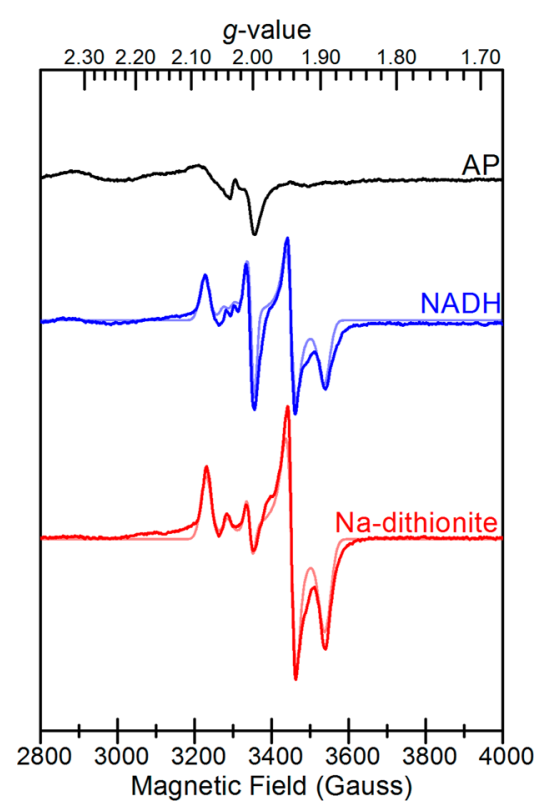

Figure 6. EPR spectra of FixABCX from A. vinelandii prepared in $50 \mathrm{mM}$ HEPES (pH 7.5), $150 \mathrm{mM} \mathrm{NaCl}$, and 5\% glycerol: black for as-prepared FixABCX $(100 \mu \mathrm{M})$, blue for FixABCX $(100 \mu \mathrm{M})$ reduced with NADH $(1 \mathrm{mM})$, and red for FixABCX $(100 \mu \mathrm{M})$ reduced with sodium dithionite $(10 \mathrm{mM})$. Simulations of spectra of $\mathrm{NADH}-$ and Na-dithionite-reduced FixABCX are shown in lighter colored traces. Settings: microwave frequency, $9.38 \mathrm{GHz}$; microwave power, $1 \mathrm{~mW}$; modulation frequency, $100 \mathrm{kHz}$; modulation amplitude, $10.0 \mathrm{G}$; sample temperature, $10 \mathrm{~K}$.

Upon reduction with either $\mathrm{NADH}$ or Na-dithionite, the broad signal almost disappeared and was replaced with multiple signals in the $S=1 / 2$ region indicative of FeS clusters and a flavin radical. Both treatments yielded overlapping rhombic $g=2.07(g=2.072$, $1.940,1.895)$ and axial $g=2.04(g=2.041,1.944,1.944)$ signals consistent with the presence of two iron-sulfur clusters, in addition to an isotropic $g=2.0$ signal consistent with a flavin radical that was dominant above $50 \mathrm{~K}$ (Figure S9). The temperature dependencies of the rhombic $g=2.07$ and axial $g=2.04$ signals were characteristic of $[4 \mathrm{Fe}-4 \mathrm{~S}]$ clusters, $^{70}$ in agreement with the sequence prediction for a pair of $[4 \mathrm{Fe}-4 \mathrm{~S}]$ clusters. The optimal temperature $\left(T_{\text {opt }}\right)$ for the rhombic $g=2.07$ signal was near $15 \mathrm{~K}$ with broadening above $30 \mathrm{~K}$ (Figure S9). The axial $g=2.04$ signal was faster relaxing with a lower $T_{\text {opt }}$ between 5 and $10 \mathrm{~K}$ and broadening above $15 \mathrm{~K}$. Also present for the NADH-reduced sample was a highly temperature dependent axial $g=2.03$ signal $(g=2.030,2.00,2.00)$ observed at $10 \mathrm{~K}$. The signal appeared to correlate with a slight loss of intensity from the axial $g=2.04$ signal compared to the $\mathrm{Na}$-dithionite treatment, suggesting that this feature could arise from the spin interaction between the faster relaxing $[4 \mathrm{Fe}-4 \mathrm{~S}]$ cluster and a flavin radical.

Further EPR analysis of the FixX subunit alone (from Ro. castenholzii) identified very similar rhombic $g=2.07$ and axial $g=2.04$ signals indicating that these signals in FixABCX originate from the FixX subunit (Figure S10). Line broadening at the high- and low-field edges of the reduced spectra was observed for both FixABCX and FixX and is indicative of spin coupling between the two [4Fe-4S] clusters. ${ }^{71}$ For FixABCX, the different relative intensities of the rhombic $g=2.07$ and axial $g=2.04$ signals suggest that the corresponding $[4 \mathrm{Fe}-4 \mathrm{~S}]$ clusters have different $E_{\mathrm{m}}$ values. Accordingly, for FixABCX, both clusters are thought to have $E_{\mathrm{m}}$ values below that of $\mathrm{Na}$-dithionite $[\leq-440 \mathrm{mV}$ vs SHE ( $\mathrm{pH} 7.5)]$, because the sample appeared to be only partially reduced by $\mathrm{Na}$-dithionite. We hypothesize that the $[4 \mathrm{Fe}-4 \mathrm{~S}]$ cluster giving rise to the axial $g=2.04$ signal has a lower $E_{\mathrm{m}}$, because of its weaker contribution to the spectrum, based on simulations (Table S4).

Altogether, the two [4Fe-4S] cluster EPR signals show a striking resemblance to the EPR signals assigned to the two [4Fe-4S] clusters in the $\mathrm{NADH}$-dependent ferredoxin:NADP ${ }^{+}$ oxidoreductase I (Nfn) bifurcating enzyme, as the signals share similar $g$ values, temperature dependence, and oxidationreduction properties. ${ }^{25}$ For the Nfn enzyme, structural and biophysical analyses showed that two $[4 \mathrm{Fe}-4 \mathrm{~S}]$ clusters in the large subunit form an electron transfer chain from the flavin site of electron bifurcation to an external ferredoxin redox partner. Spin coupling between the two clusters is thought to facilitate electron transfer between the redox cofactors. It was also found for the Nfn enzyme that one of the [4Fe-4S] clusters had an unusually low $E_{\mathrm{m}}$ that creates a thermodynamically favorable electron transfer pathway from a highly unstable semiquinone intermediate formed during electron bifurcation. An analogous model is suggested here for FixABCX where the two lowpotential $[4 \mathrm{Fe}-4 \mathrm{~S}]$ clusters in the FixX subunit would form a thermodynamically favorable pathway for facile electron transfer between the site of bifurcation and Fd/Fld.

Electron Bifurcation by the FixABCX Complex. Electron bifurcation by the FixABCX complex is proposed to drive the endergonic reduction of $\mathrm{Fld}^{\mathrm{Sq}}$ by coupling it to the exergonic reduction of $\mathrm{CoQ}$ using $\mathrm{NADH}$ as an electron donor (Figures 2 and $7 \mathrm{~A}$ ). Electron bifurcation by the FixABCX complex was demonstrated by incubating FixABCX with the electron donor $\mathrm{NADH}$, high-potential acceptor coenzyme $\mathrm{Q}_{\mathrm{C}}\left(\mathrm{CoQ}_{1}\right)$, and lowpotential acceptor $\mathrm{Fld}^{\mathrm{Sq}}$. $\mathrm{CoQ}$ served as an amphipathic analogue of the physiological acceptor coenzyme $\mathrm{Q}_{8}\left(\mathrm{CoQ}_{8}\right)$ found in the electron transport chain of $A$. vinelandii. ${ }^{72,73}$ Fld $^{\text {Sq }}$ was used as the low-potential acceptor in these assays because Fld $^{\mathrm{Hq}}$ has been shown to directly donate electrons to nitrogenase. ${ }^{5,6}$ Similarly, the previously characterized electron bifurcating Etf-Bcd complex could direct electrons to either Fd or Fld, ${ }^{22,23}$ suggesting that Fld could likely serve as an electron acceptor from FixABCX, as well.

For the electron bifurcation assay, the oxidation of NADH $(340 \mathrm{~nm})$, disappearance of $\mathrm{Fld}^{\mathrm{Sq}}(580 \mathrm{~nm})$, and formation of $\mathrm{Fld}^{\mathrm{Ox}}(450 \mathrm{~nm})$ were monitored over time. $\mathrm{CoQ}$ reduction $\left(\lambda_{\max }=274 \mathrm{~nm}\right)$ was not recorded, because of significant interference at that wavelength. While the simultaneous presence of several redox active components in the assays posed a challenge, monitoring activities at multiple wavelengths provided evidence of electron bifurcation. Control reactions for $\mathrm{NADH}$ oxidation (diaphorase) activity linked to $\mathrm{CoQ}_{1}$ reduction in the absence of Fld ${ }^{\mathrm{Sq}}$ yielded a specific activity of $396 \pm 44 \mathrm{nmol}$ $\mathrm{min}^{-1} \mathrm{mg}^{-1}$ with a turnover frequency of $51 \pm 6 \mathrm{~min}^{-1}$ [Figure $7 \mathrm{~B}$ (No Fld $\left.\left.{ }^{\mathrm{Sq}}\right)\right]$. Bifurcation reaction mixtures containing the additional component needed for bifurcation ( $\mathrm{Fld}^{\mathrm{Sq}}$, in addition to the control reactants FixABCX, NADH, and $\mathrm{CoQ}_{1}$ ) exhibited $25 \%$ greater $\mathrm{NADH}$ oxidation activity with a specific activity of $524 \pm 21 \mathrm{nmol} \mathrm{min} \mathrm{mg}^{-1}$ and a turnover frequency of $68 \pm 3 \mathrm{~min}^{-1}$ [Figure 7B (All components)]. It is important to note that the specific activity values are not adjusted for flavin occupancy, because it could not be confirmed how much of the 


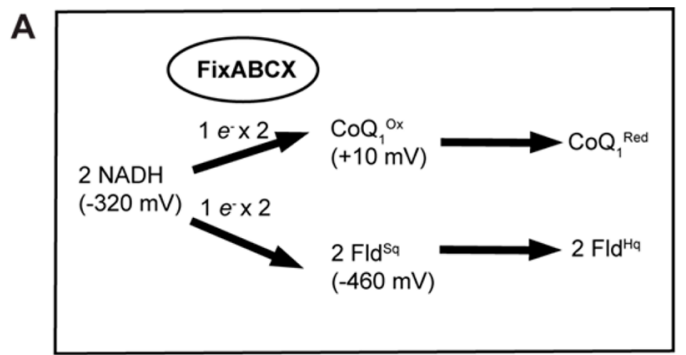

B

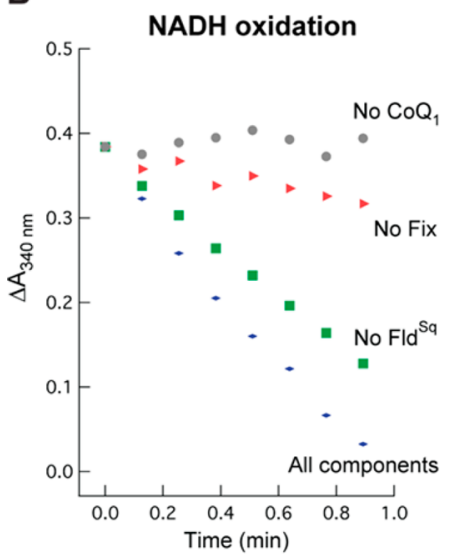

C

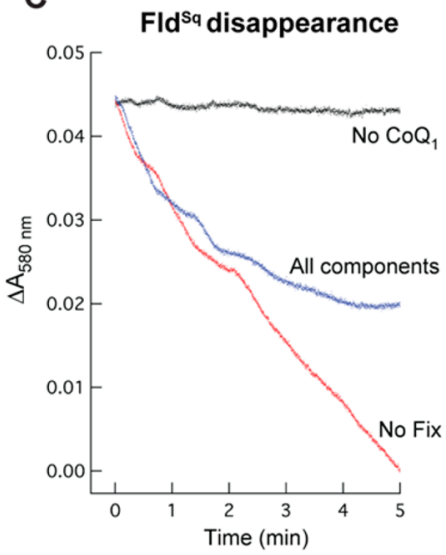

D

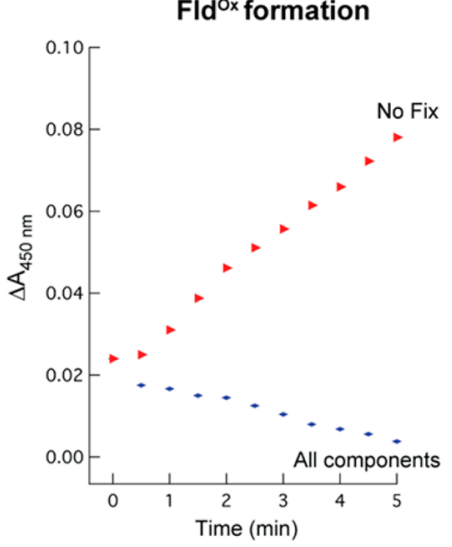

Figure 7. Electron bifurcation by the FixABCX complex of A. vinelandii under anaerobic conditions. (A) Overview of electron bifurcation by the FixABCX complex showing the NADH bifurcating an electron to the high-potential acceptor, $\mathrm{CoQ}_{4}$, and the other to the low-potential acceptor, Fld ${ }^{\mathrm{Sq}}$. Evidence of electron bifurcation was obtained using UV-vis spectrophotometry. NADH oxidation as well as Fld ${ }^{\mathrm{Sq}}$ reduction and oxidation were monitored over time as signatures of the bifurcation reaction. (B) NADH oxidation at $340 \mathrm{~nm}$, (C) Fld ${ }^{\mathrm{Sq}}$ reduction/oxidation at $580 \mathrm{~nm}$, and (D) formation of Fld ${ }^{\mathrm{Ox}}$ at $450 \mathrm{~nm}$. Final concentrations of components added to the reaction mixtures were as follows: $0.8 \mu \mathrm{M}$ FixABCX, $85 \mu \mathrm{M}$ Fld ${ }^{\mathrm{Sq}}$, $200 \mu \mathrm{M} \mathrm{NADH}$, and $300 \mu \mathrm{M} \mathrm{CoQ}$. Data were normalized and demonstrate the overall change in absorbance.

protein was fully occupied (how flavins were distributed among the flavin binding sites).

The Fld-dependent increase in the level of NADH consumption is consistent with bifurcation, and previous studies of the Etf-Bcd bifurcating complex also demonstrated an increased level of $\mathrm{NADH}$ consumption in a bifurcating reaction. $^{22,23}$ Omission of FixABCX or $\mathrm{CoQ}_{\text {r }}$ resulted in baseline $\mathrm{NADH}$ oxidation activity (Figure $7 \mathrm{~B}$ ). To decipher whether the enhanced consumption of $\mathrm{NADH}$ in the presence of Fld ${ }^{\mathrm{Sq}}$ could be attributed to the endergonic reduction of $\mathrm{Fld}^{\mathrm{Sq}}$ to $\mathrm{Fld}^{\mathrm{Hq}}$ (the bifurcation reaction), the disappearance of $\mathrm{Fld}^{\mathrm{Sq}}$ was monitored at $580 \mathrm{~nm}$ where optical absorption by the hydroquinone species is negligible but absorbance by the semiquinone is strong $\left(\varepsilon=5.7 \mathrm{mM}^{-1} \mathrm{~cm}^{-1}\right)$. Reactions monitoring the disappearance of $\mathrm{Fld}^{\mathrm{Sq}}$ were difficult to interpret on their own, because of background activity in the absence of FixABCX (Figure 7C). In vivo, $\mathrm{CoQ}$ is in the membrane, whereas Fld is in the cytoplasm; therefore, the extent of direct contact between them is diminished, and spontaneous electron transfer between the two species is suppressed (Table S5). In vitro experiments however lack this separation, and our controls revealed that Fld $^{\mathrm{Sq}}$ can donate electrons to $\mathrm{CoQ}_{1}$ in the absence of FixABCX (Figure $7 \mathrm{C}$ ). Thus, the $\mathrm{Fld}^{\mathrm{Sq}}$ concentration decreased, while an increase at $450 \mathrm{~nm}$, characteristic of $\mathrm{Fld}^{\mathrm{Ox}}$, was observed (Figure 7D). This nonenzymatic reduction of $\mathrm{CoQ}$ by $\mathrm{Fld}^{\mathrm{Sq}}$ is consistent with the favorable $\Delta G^{\circ}$ of $-36.7 \mathrm{~kJ} / \mathrm{mol}$ (Table S5). However, the increase in absorbance at $450 \mathrm{~nm}$ produced by spontaneous $\mathrm{Fld}^{\mathrm{Sq}}$ oxidation enabled us to account for this reaction that detracts from the apparent yield of the bifurcating reaction [Figure 7C (All components)]. The Fld ${ }^{\mathrm{Ox}}$ species was not detected in the bifurcating reaction assays, indicating that $\mathrm{Fld}^{\mathrm{Hq}}$, the expected product of the bifurcation reaction, was formed instead (Figure 7D). However, we do not expect Fld $^{\mathrm{Hq}}$ to accumulate in the presence of $\mathrm{CoQ}$, because of the favorability of electron transfer between these two that will return Fld to its semiquinone state and thus conceal the true extent of Fld ${ }^{\mathrm{Hq}}$ production $\left(\Delta G^{\circ}=-154 \mathrm{~kJ} / \mathrm{mol}\right)$ (eq 4 and Table S5).

$$
\begin{gathered}
\mathrm{NADH}+2 \mathrm{Fld}^{\mathrm{Hq}}+2 \mathrm{CoQ}+3 \mathrm{H}^{+} \\
=2 \mathrm{CoQH}_{2}+2 \mathrm{Fld}^{\mathrm{Sq}}+\mathrm{NAD}^{+}
\end{gathered}
$$

Overall, the absence of $\mathrm{Fld}^{\mathrm{Ox}}$ in conjunction with the increased activity of the electron bifurcation reaction in comparison to diaphorase activity suggests that the FixABCX complex can in fact perform electron bifurcation. To further investigate the flavin cofactors in FixABCX, transient absorption spectroscopy (TAS) was conducted.

Transient Absorption Spectroscopy. A comparative TAS study between FixAB from Rh. rubrum and FixABCX from $A$. vinelandii was performed to gain qualitative information about spectral contributions from individual flavins. TAS of the incomplete Fix complex, FixAB, revealed an anionic semiquinone (ASQ) absorption at $365 \mathrm{~nm}$ with a corresponding oxidized (Ox) flavin bleach at $447 \mathrm{~nm}$. The ASQ absorption decays with two components: a short-lived component with a lifetime of tens of picoseconds and a longer short-lived component with a lifetime of 1000 picoseconds [Figure 8A (red trace) and Table S6]. A similar ASQ signal was also observed in the 

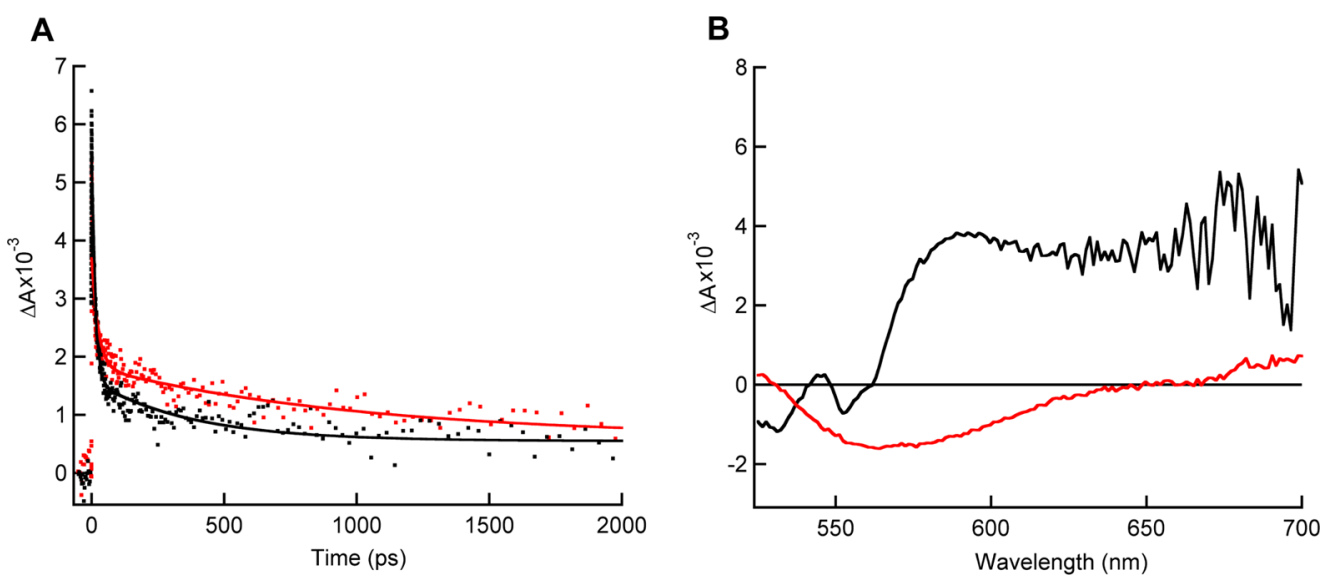

Figure 8. Transient absorption spectra of as-prepared Rh. rubrum FixAB (red) and A. vinelandii FixABCX (black). (A) Kinetic traces of ASQ signal (dots) at $365 \mathrm{~nm}$. ASQ decay shows half-lives of $\sim 15$ and $\sim 1000 \mathrm{ps}$ when fit with a double-exponential function (solid lines). (B) An NSQ absorption peak $(\sim 565-650 \mathrm{~nm})$ is observed only for the A. vinelandii FixABCX complex.

A. vinelandii FixABCX complex [Figure 8A (black trace)]. This suggests that two ASQ species can be formed in the FixAB unit, consistent with the presence of two flavins. Bifurcating flavins have been shown to exhibit crossed potentials, whereby the $E_{\mathrm{m}}{ }^{\mathrm{Ox} / \mathrm{SQ}}$ is at a potential lower than that of $E_{\mathrm{m}}^{\mathrm{SQ} / \mathrm{HQ}}$, the result being that the high-energy SQ intermediate does not appreciably accumulate relative to $\mathrm{Ox}$ and $\mathrm{HQ}$.

A short-lived ASQ has been observed in the bifurcating Nfn from Pyrococcus furiosus and is proposed to play a central role in bifurcation. ${ }^{19,25}$ The current observation of relatively short-lived ASQ signals in Rh. rubrum FixAB and A. vinelandii FixABCX is consistent with the work on Nfn and suggests that neither flavin significantly stabilizes a one-electron-reduced species. On the basis of comparison with Etf, the flavin in FixA (a-FAD) (analogous to the $\beta$-FAD in $\mathrm{EtfB}$ ) is the proposed site of bifurcation and likely corresponds to the component of tens of picoseconds in our TAS experiments. ${ }^{22}$ This assignment then implies that the FixB b-FAD acts as an electron transferring flavin, consistent with a slightly longer-lived ASQ because accumulation of electrons at this site may congest electron flow and impede bifurcation. This may additionally play a role in gating electron transfer, ensuring that only one electron follows the exergonic path, and thus restricting the lower-potential electron to travel down the endergonic branch, similar to the mechanism of electron bifurcation in P. furiosus $\mathrm{Nfn}^{25}$ Because of the crossed potentials believed to characterize bifurcating flavins, the more negative potential electron of the bifurcating flavin (ASQ to Ox transition) would provide enough driving force to reduce the low-potential iron-sulfur clusters [predicted to be $\leq-440 \mathrm{mV}$ vs SHE ( $\mathrm{pH} 7.5)]$ in FixX directly. In the complete FixABCX complex from $A$. vinelandii, an additional peak is observed in the TAS corresponding to a neutral semiquinone (NSQ) and is assigned to the c-FAD in FixC (Figure 8B). We propose two electrons from successive bifurcations accumulate in $\mathrm{c}-\mathrm{FAD}$ to permit two-electron reduction of CoQ.

Proposed Mechanism for FixABCX Electron Bifurcation. The data presented herein establish that the FixABCX complex from A. vinelandii can bifurcate electrons from $\mathrm{NADH}$ to $\mathrm{CoQ}$ and $\mathrm{Fld}^{\mathrm{Sq}}$. The biochemical and biophysical evidence is consistent with a proposed mechanism of Fix electron bifurcation initiated at the flavin in FixA, which would accept a pair of electrons from $\mathrm{NADH}$ and pass one electron to the quinone pool via the flavins in FixB and FixC, and the other to
Fld/Fd via the low-potential [4Fe-4S] clusters in FixX, with the energetic cost being paid by favorable transfer of the former electron to the quinone pool (Figure 2).

TAS on the FixABCX complex provides evidence by demonstrating the presence of a short-lived anionic flavin semiquinone consistent with the ability to support rapid and efficient electron transfer. The findings here provide experimental support for the mechanism proposed previously for a homologous bifurcating Etf that assigns the site of bifurcation to the flavin bound by FixA (EtfB). ${ }^{22}$ This assignment is further supported by the demonstration by Sato et al. that the flavin reduced by $\mathrm{NADH}$ is the one bound in FixA (EtfB), but that electron transfer to the flavin in FixB (EtfA) is favorable. ${ }^{39}$ Thus, upon reduction of the FixA flavin, transfer of an electron through the exergonic branch to $\mathrm{CoQ}$ via FixB and FixC can leave the second electron in a very unstable, highly energetic flavin semiquinone state with a low $E_{\mathrm{m}}{ }^{\mathrm{Ox} / \mathrm{Sq}}$ that can drive reduction of Fld/Fd, via FixX (Figure 2).

The mechanism presented here offers a means by which $\mathrm{Fd} /$ Fld can be reduced by $\mathrm{NADH}$ in a reaction that is thermodynamically favorable overall and identifies a new pathway by which low-potential reducing equivalents can be generated to drive nitrogen fixation.

\section{ASSOCIATED CONTENT}

Primers for $\Delta f i x$ mutant generation (Table S1), primers for overexpression of FixABCX (Table S2), proteinprotein interactions captured within the FixABCX complex during chemical cross-linking reaction (Table S3), overview of the EPR signals observed for FixABCX from A. vinelandii (Table S4), calculated Gibbs free energies of possible reactions catalyzed by the Fix complex and possible nonenzymatic reactions (Table S5), lifetimes of ASQ species from $R h$. rubrum FixAB and $A$. vinelandii FixABCX (Table S6), scheme for $\Delta f i x$ mutant generation (Figure S1), scheme for overexpression of fix genes in A. vinelandii (Figure S2), protein identification within the FixABCX complex purified from A. vinelandii (Figure S3), DLS of the FixABCX complex (Figure S4), evaluation of subunit homology models (Figure S5), predicted 
structural features in Fix subunits (Figure S6), FixB protein interface (Figure S7), structural model of the FixABCX complex from $A$. vinelandii (Figure S8), EPR temperature profiles of FixABCX from $A$. vinelandii (Figure S9), and comparison of EPR spectra of FixABCX from $A$. vinelandii and the individual FixX subunit from Ro. castenholzii (Figure S10) (PDF)

\section{ACKNOWLEDGMENTS}

The authors thank Stefan Nordlund at Stockholm University and Tomas Edgren at Umeå University for the plasmid containing Rh. rubrum FixAB and their guidance in Fix protein expression and purification and Luis Rubio for the $A$. vinelandii rnf mutants. The authors also acknowledge Utah State University's Synthetic Biomanufacturing Institute for conducting large-scale fermentations and Montana State University's Microfabrication Facility for help in the preparation of gold-coated borosilica capillaries for noncovalent mass spectrometry. The Mass Spectrometry Facility at Montana State University is supported in part by the Murdock Charitable Trust and National Institutes of Health IDEA Program Grant P20GM103474.

\section{ABBREVIATIONS}

AEBSF, 4-(2-aminoethyl)benzenesulfonyl fluoride hydrochloride; $\mathrm{Amp}^{\mathrm{S}}$, ampicillin sensitivity; ASQ anionic semiquinone; $\mathrm{BBO}$, beta barium borate; $\mathrm{BS} 3$, bis(sulfosuccinimidyl)suberate; CoQ coenzyme $Q_{i}$ CoQ , coenzyme $Q_{1}$; CoQ ${ }_{s}$, coenzyme $Q_{8}$; DDM, dodecyl maltoside; DLS, dynamic light scattering; DTT, dithiothreitol; Etf, electron transfer flavoprotein; Etf-Bcd, electron transferring flavoprotein/butyryl-coenzyme A; ETF-QO, electron transferring flavoprotein ubiquinone oxidoreductase; $E_{\mathrm{m}}$ midpoint potential; EPR, electron paramagnetic resonance; $\mathrm{FAD}$, flavin adenine dinucleotide; $\mathrm{Fd}$, ferredoxin; Fld, flavodoxin; $\mathrm{Fld}^{\mathrm{Ox}}$, oxidized quinone; $\mathrm{Fld}^{\mathrm{Hq}}$, flavodoxin hydroquinone; Fld ${ }^{\mathrm{Sq}}$, flavodoxin semiquinone; IPTG, isopropyl $\beta$-D-1-thiogalactopyranoside; $\mathrm{Km}^{\mathrm{R}}$, kanamycin resistance; LB, LuriaBertani; LC-MS/MS, liquid chromatography with tandem mass spectrometry; MS, mass spectrometry; Na-dithionite, sodium dithionite; $\mathrm{Nif}^{+}$, nitrogen-fixing phenotype; Nif ${ }^{-}$, non-nitrogenfixing phenotype; PCR, polymerase chain reaction; PMSF, phenylmethanesulfonyl fluoride; Rf, riboflavin; Rnf, Rhodobacter nitrogen fixation; $\mathrm{Sm}^{\mathrm{R}}$, streptomycin resistance; TAS, transient absorption spectroscopy; TCEP, tris(2-carboxyethyl)phosphine; $\mathrm{TB}$, terrific broth; $T_{\text {opv }}$ optimal temperature.

\section{REFERENCES}

(1) Kim, J., and Rees, D. C. (1994) Nitrogenase and biological nitrogen fixation. Biochemistry 33, 389-397.

(2) Burgess, B. K., and Lowe, D. J. (1996) Mechanism of molybdenum nitrogenase. Chem. Rev. 96, 2983-3012.

(3) Seefeldt, L. C., Hoffman, B. M., and Dean, D. R. (2009) Mechanism of Mo-dependent nitrogenase. Annu. Rev. Biochem. 78, 701-722.

(4) Saeki, K. (2004) Electron transport to nitrogenase: Diverse routes for a common destination. In Genetics and Regulation of Nitrogen Fixation in Free-living Bacteria (Klipp, W., Masepohl, B., Gallon, J. R., and Newton, W. E., Eds.) pp 257-290, Kluwer Academic Publishers, Dordrecht, The Netherlands.

(5) Yang, Z. Y., Ledbetter, R., Shaw, S., Pence, N., TokminaLukaszewska, M., Eilers, B., Guo, Q., Pokhrel, N., Cash, V. L., Dean, D. R., Antony, E., Bothner, B., Peters, J. W., and Seefeldt, L. C. (2016) Evidence that the $\mathrm{Pi}$ release event is the rate-limiting step in the nitrogenase catalytic cycle. Biochemistry 55, 3625-3635.

(6) Martin, A. E., Burgess, B. K., Iismaa, S. E., Smartt, C. T., Jacobson, M. R., and Dean, D. R. (1989) Construction and characterization of an Azotobacter vinelandii strain with mutations in the genes encoding flavodoxin and ferredoxin I. J. Bacteriol. 171, 3162-3167.

(7) Deistung, J., and Thorneley, R. N. (1986) Electron transfer to nitrogenase: Characterization of flavodoxin from Azotobacter chroococcum and comparison of its redox potentials with those of flavodoxins from Azotobacter vinelandii and Klebsiella pneumoniae (nifF-gene product). Biochem. J. 239, 69-75.

(8) Mortenson, L. E. (1964) Ferredoxin and ATP, requirements for nitrogen fixation in cell-free extracts of Clostridium pasteurianum. Proc. Natl. Acad. Sci. U. S. A. 52, 272-279.

(9) Yates, M. G. (1972) Electron transport to nitrogenase in Azotobacter chroococcum: Azotobacter flavodoxin hydroquinone as an electron donor. FEBS Lett. 27, 63-67.

(10) Thorneley, R. N., and Deistung, J. (1988) Electron-transfer studies involving flavodoxin and a natural redox partner, the iron protein of nitrogenase: Conformational constraints on protein-protein interactions and the kinetics of electron transfer within the protein complex. Biochem. J. 253, 587-595.

(11) Cammack, R. (1992) Iron-sulfur clusters in enzymes: Themes and variations. In Advances in Inorganic Chemistry (Cammack, R., Ed.) pp 281-322, Academic Press, San Diego.

(12) Klugkist, J., Voorberg, J., Haaker, H., and Veeger, C. (1986) Characterization of three different flavodoxins from Azotobacter vinelandii. Eur. J. Biochem. 155, 33-40.

(13) Ludden, P. W. (1991) Energetics of and sources of energy for biological nitrogen fixation. In Current Topics in Bioenergetics (Lee, C. P., Ed.) pp 369-390, Academic Press, San Diego.

(14) Shah, V. K., Stacey, G., and Brill, W. J. (1983) Electron transport to nitrogenase. Purification and characterization of pyruvate:flavodoxin oxidoreductase. The nifJ gene product. J. Biol. Chem. 258, 1206412068.

(15) Saeki, K., and Kumagai, H. (1998) The rnf gene products in Rhodobacter capsulatus play an essential role in nitrogen fixation during anaerobic DMSO-dependent growth in the dark. Arch. Microbiol. 169, 464-467.

(16) Schmehl, M., Jahn, A., Meyer zu Vilsendorf, A., Hennecke, S., Masepohl, B., Schuppler, M., Marxer, M., Oelze, J., and Klipp, W. (1993) Identification of a new class of nitrogen fixation genes in Rhodobacter capsalatus: A putative membrane complex involved in electron transport to nitrogenase. Mol. Gen. Genet. 241, 602-615.

(17) Buckel, W., and Thauer, R. K. (2013) Energy conservation via electron bifurcating ferredoxin reduction and proton/ $\mathrm{Na}+$ translocating ferredoxin oxidation. Biochim. Biophys. Acta, Bioenerg. 1827, 94-113.

(18) Peters, J. W., Miller, A. F., Jones, A. K., King, P. W., and Adams, M. W. (2016) Electron bifurcation. Curr. Opin. Chem. Biol. 31, 146-152.

(19) Nitschke, W., and Russell, M. J. (2012) Redox bifurcations: Mechanisms and importance to life now, and at its origin. BioEssays 34, 106-109. 
(20) Herrmann, G., Jayamani, E., Mai, G., and Buckel, W. (2008) Energy conservation via electron-transferring flavoprotein in anaerobic bacteria. J. Bacteriol. 190, 784-791.

(21) Li, F., Hinderberger, J., Seedorf, H., Zhang, J., Buckel, W., and Thauer, R. K. (2008) Coupled rerredoxin and crotonyl coenzyme A (CoA) reduction with $\mathrm{NADH}$ catalyzed by the butyryl-CoA dehydrogenase/Etf complex from Clostridium kluyveri. J. Bacteriol. 190, 843-850.

(22) Chowdhury, N. P., Mowafy, A. M., Demmer, J. K., Upadhyay, V., Koelzer, S., Jayamani, E., Kahnt, J., Hornung, M., Demmer, U., Ermler, U., and Buckel, W. (2014) Studies on the mechanism of electron bifurcation catalyzed by electron transferring flavoprotein (Etf) and butyryl-CoA dehydrogenase (Bcd) of Acidaminococcus fermentans. J. Biol. Chem. 289, 5145-5157.

(23) Chowdhury, N. P., Klomann, K., Seubert, A., and Buckel, W. (2016) Reduction of flavodoxin by electron bifurcation and sodium iondependent re-oxidation by $\mathrm{NAD}^{+}$catalysed by ferredoxin:NA$\mathrm{D}^{+}$reductase (Rnf). J. Biol. Chem. 291, 11993-12002.

(24) Bertsch, J., Parthasarathy, A., Buckel, W., and Müller, V. (2013) An electron-bifurcating caffeyl-CoA reductase. J. Biol. Chem. 288, 11304-11311.

(25) Lubner, C. E., Jennings, D. P., Mulder, D. W., Schut, G. J., Zadvornyy, O. A., Hoben, J., Tokmina-Lukaszewska, M., Berry, L., Nguyen, D., Lipscomb, G. L., Bothner, B., Jones, A. K., Miller, A. F., King, P. W., Adams, M. W. W., and Peters, J. W. (2017) Mechanistic insights into energy conservation by flavin-based electron bifurcation. Nat. Chem. Biol. 13, 655-659.

(26) Edgren, T. (2006) Electron transport to nitrogenase, Stockholm University, Stockholm.

(27) Wientjens, R. (1993) The involvement of the fixABCX genes and the respiratory chain in the electron transport to nitrogenase in Azotobacter vinelandii. The Department of Chemistry and Biochemistry, Agricultural University, Wageningen, The Netherlands.

(28) Huang, J. J., Heiniger, E. K., McKinlay, J. B., and Harwood, C. S. (2010) Production of hydrogen gas from light and the inorganic electron donor thiosulfate by Rhodopseudomonas palustris. Appl. Environ. Microbiol. 76, 7717-7722.

(29) Edgren, T., and Nordlund, S. (2004) The fix $A B C X$ genes in Rhodospirillum rubrum encode a putative membrane complex participating in electron transfer to nitrogenase. J. Bacteriol. 186, 2052-2060.

(30) Ruvkun, G. B., Sundaresan, V., and Ausubel, F. M. (1982) Directed transposon Tn5 mutagenesis and complementation analysis of Rhizobium meliloti symbiotic nitrogen fixation genes. Cell 29, 551-559.

(31) Earl, C. D., Ronson, C. W., and Ausubel, F. M. (1987) Genetic and structural analysis of the Rhizobium meliloti fixA, fixB, fixC, and fixX genes. J. Bacteriol. 169, 1127-1136.

(32) Curatti, L., Brown, C. S., Ludden, P. W., and Rubio, L. M. (2005) Genes required for rapid expression of nitrogenase activity in Azotobacter vinelandii. Proc. Natl. Acad. Sci. U. S. A. 102, 6291-6296.

(33) de Lorenzo, V., Herrero, M., Jakubzik, U., and Timmis, K. N. (1990) Mini-Tn5 transposon derivatives for insertion mutagenesis, promoter probing, and chromosomal insertion of cloned DNA in gramnegative eubacteria. J. Bacteriol. 172, 6568-6572.

(34) Page, W. J., and von Tigerstrom, M. (1979) Optimal conditions for transformation of Azotobacter vinelandii. J. Bacteriol. 139, 10581061.

(35) Jacobson, M. R., Cash, V. L., Weiss, M. C., Laird, N. F., Newton, W. E., and Dean, D. R. (1989) Biochemical and genetic analysis of the nifUSVWZM cluster from Azotobacter vinelandii. Mol. Gen. Genet. 219, $49-57$.

(36) Toukdarian, A., and Kennedy, C. (1986) Regulation of nitrogen metabolism in Azotobacter vinelandii: isolation of $n t r$ and $g \ln A$ genes and construction of ntr mutants. EMBO J. 5, 399-407.

(37) Sarma, R., Barney, B. M., Hamilton, T. L., Jones, A., Seefeldt, L. C., and Peters, J. W. (2008) Crystal structure of the L protein of Rhodobacter sphaeroides light-independent protochlorophyllide reductase with $\mathrm{MgADP}$ bound: a homologue of the nitrogenase $\mathrm{Fe}$ protein. Biochemistry 47, 13004-13015.
(38) Lewis, J. A., and Escalante-Semerena, J. C. (2006) The FADdependent tricarballylate dehydrogenase (TcuA) enzyme of Salmonella enterica converts tricarballylate into cis-aconitate. J. Bacteriol. 188, 54795486.

(39) Sato, K., Nishina, Y., and Shiga, K. (2013) Interaction between $\mathrm{NADH}$ and electron-transferring flavoprotein from Megasphaera elsdenii. J. Biochem. 153, 565-572.

(40) Vaudel, M., Burkhart, J. M., Zahedi, R. P., Oveland, E., Berven, F. S., Sickmann, A., Martens, L., and Barsnes, H. (2015) PeptideShaker enables reanalysis of MS-derived proteomics data sets. Nat. Biotechnol. $33,22-24$.

(41) Lima, D. B., de Lima, T. B., Balbuena, T. S., Neves-Ferreira, A. G. C., Barbosa, V. C., Gozzo, F. C., and Carvalho, P. C. (2015) SIM-XL: A powerful and user-friendly tool for peptide cross-linking analysis. $J$. Proteomics 129, 51-55.

(42) Poudel, S., Tokmina-Lukaszewska, M., Colman, D. R., Refai, M., Schut, G. J., King, P. W., Maness, P. C., Adams, M. W. W., Peters, J. W., Bothner, B., and Boyd, E. S. (2016) Unification of [FeFe]-hydrogenases into three structural and functional groups. Biochim. Biophys. Acta, Gen. Subj. 1860, 1910-1921.

(43) Luo, M. L., Jackson, R. N., Denny, S. R., Tokmina-Lukaszewska, M., Maksimchuk, K. R., Lin, W., Bothner, B., Wiedenheft, B., and Beisel, C. L. (2016) The CRISPR RNA-guided surveillance complex in Escherichia coli accommodates extended RNA spacers. Nucleic Acids Res. 44, 7385-7394.

(44) Kelley, L. A., Mezulis, S., Yates, C. M., Wass, M. N., and Sternberg, M. J. E. (2015) The Phyre2 web portal for protein modeling, prediction and analysis. Nat. Protoc. 10, 845-858.

(45) Kozakov, D., Beglov, D., Bohnuud, T., Mottarella, S. E., Xia, B., Hall, D. R., and Vajda, S. (2013) How good is automated protein docking? Proteins: Struct., Funct., Genet. 81, 2159-2166.

(46) Kozakov, D., Brenke, R., Comeau, S. R., and Vajda, S. (2006) PIPER: an FFT-based protein docking program with pairwise potentials. Proteins: Struct., Funct., Genet. 65, 392-406.

(47) Comeau, S. R., Gatchell, D. W., Vajda, S., and Camacho, C. J. (2004) ClusPro: an automated docking and discrimination method for the prediction of protein complexes. Bioinformatics 20, 45-50.

(48) Comeau, S. R., Gatchell, D. W., Vajda, S., and Camacho, C. J. (2004) ClusPro: a fully automated algorithm for protein-protein docking. Nucleic Acids Res. 32, W96-99.

(49) Grosdidier, A., Zoete, V., and Michielin, O. (2011) SwissDock, a protein-small molecule docking web service based on EADock DSS. Nucleic Acids Res. 39, W270-277.

(50) Grosdidier, A., Zoete, V., and Michielin, O. (2011) Fast docking using the CHARMM force field with EADock DSS. J. Comput. Chem. 32, 2149-2159.

(51) Pettersen, E. F., Goddard, T. D., Huang, C. C., Couch, G. S., Greenblatt, D. M., Meng, E. C., and Ferrin, T. E. (2004) UCSF Chimera-a visualization system for exploratory research and analysis. J. Comput. Chem. 25, 1605-1612.

(52) McComb, R. B., Bond, L. W., Burnett, R. W., Keech, R. C., and Bowers, G. N. (1976) Determination of the molar absorptivity of NADH. Clin. Chem. 22, 141-150.

(53) Enescu, M., Lindqvist, L., and Soep, B. (1998) Excited-state dynamics of fully reduced flavins and flavoenzymes studied at subpicosecond time resolution. Photochem. Photobiol. 68, 150-156.

(54) Wang, Z., and Zhang, J. (2009) Abundant indispensable redundancies in cellular metabolic networks. Genome Biol. Evol. 1, 23-33.

(55) Jeong, H. S., and Jouanneau, Y. (2000) Enhanced nitrogenase activity in strains of Rhodobacter capsulatus that overexpress the rnf genes. J. Bacteriol. 182, 1208-1214.

(56) Sarkar, A., Köhler, J., Hurek, T., and Reinhold-Hurek, B. (2012) A novel regulatory role of the Rnf complex of Azoarcus sp. strain BH72. Mol. Microbiol. 83, 408-422.

(57) Boyd, E. S., Costas, A. M. G., Hamilton, T. L., Mus, F., and Peters, J. W. (2015) Evolution of molybdenum nitrogenase during the transition from anaerobic to aerobic metabolism. J. Bacteriol. 197, $1690-1699$ 
(58) Markowitz, V. M., Chen, I. M. A., Palaniappan, K., Chu, K., Szeto, E., Grechkin, Y., Ratner, A., Jacob, B., Huang, J., Williams, P., Huntemann, M., Anderson, I., Mavromatis, K., Ivanova, N. N., and Kyrpides, N. C. (2012) IMG: the Integrated Microbial Genomes database and comparative analysis system. Nucleic Acids Res. 40, D115122.

(59) Reyntjens, B., Jollie, D. R., Stephens, P. J., Gao-Sheridan, H. S., and Burgess, B. K. (1997) Purification and characterization of a fixABCX-linked 2[4Fe-4S] ferredoxin from Azotobacter vinelandii. JBIC, J. Biol. Inorg. Chem. 2, 595-602.

(60) Watmough, N. J., and Frerman, F. E. (2010) The electron transfer flavoprotein: Ubiquinone oxidoreductases. Biochim. Biophys. Acta, Bioenerg. 1797, 1910-1916.

(61) Usselman, R. J., Fielding, A. J., Frerman, F. E., Watmough, N. J., Eaton, G. R., and Eaton, S. S. (2008) Impact of mutations on the midpoint potential of the $[4 \mathrm{Fe}-4 \mathrm{~S}]^{+1,+2}$ cluster and on catalytic activity in electron transfer flavoprotein-ubiquinone oxidoreductase (ETF-QO). Biochemistry 47, 92-100.

(62) Jones, D. T., Taylor, W. R., and Thornton, J. M. (1994) A model recognition approach to the prediction of all-helical membrane protein structure and topology. Biochemistry 33, 3038-3049.

(63) le Maire, M., Champeil, P., and Møller, J. V. (2000) Interaction of membrane proteins and lipids with solubilizing detergents. Biochim. Biophys. Acta, Biomembr. 1508, 86-111.

(64) Sweeney, W. V., and Rabinowitz, J. C. (1980) Proteins Containing 4Fe-4S Clusters: An Overview. Annu. Rev. Biochem. 49, 139-161.

(65) Zhang, J., Frerman, F. E., and Kim, J.-J. P. (2006) Structure of electron transfer flavoprotein-ubiquinone oxidoreductase and electron transfer to the mitochondrial ubiquinone pool. Proc. Natl. Acad. Sci. U.S. A. 103, 16212-16217.

(66) Demmer, J. K., Rupprecht, F. A., Eisinger, M. L., Ermler, U., and Langer, J. D. (2016) Ligand binding and conformational dynamics in a flavin-based electron-bifurcating enzyme complex revealed by Hydrogen-Deuterium Exchange Mass Spectrometry. FEBS Lett. 590, 44724479.

(67) Dryhurst, G., and Elving, P. J. (1969) Electrochemical oxidationreduction paths for pyrimidine, cytosine, purine and adenine: Correlation and application. Talanta 16, 855-874.

(68) Bonetti, C., Stierl, M., Mathes, T., van Stokkum, I. H. M., Mullen, K. M., Cohen-Stuart, T. A., van Grondelle, R., Hegemann, P., and Kennis, J. T. M. (2009) The role of key amino acids in the photoactivation pathway of the Synechocystis Slr1694 BLUF domain. Biochemistry 48, 11458-11469.

(69) Gray, H. B., and Winkler, J. R. (2015) Hole hopping through tyrosine/tryptophan chains protects proteins from oxidative damage. Proc. Natl. Acad. Sci. U. S. A. 112, 10920-10925.

(70) Rupp, H., Rao, K. K., Hall, D. O., and Cammack, R. (1978) Electron spin relaxation of iron-sulphur proteins studied by microwave power saturation. Biochim. Biophys. Acta, Protein Struct. 537, 255-269.

(71) Mathews, R., Charlton, S., Sands, R. H., and Palmer, G. (1974) On the nature of the spin coupling between the iron-sulfur clusters in the eight-iron ferredoxins. J. Biol. Chem. 249, 4326-4328.

(72) Swank, R. T., and Burris, R. H. (1969) Restoration by ubiquinone of Azotobacter vinelandii reduced nicotinamide adenine dinucleotide oxidase activity. J. Bacteriol. 98, 311-313.

(73) Knowles, C. J., and Redfearn, E. R. (1969) Cytochrome and ubiquinone patterns during growth of Azotobacter vinelandii. J. Bacteriol. 97, 756-760. 